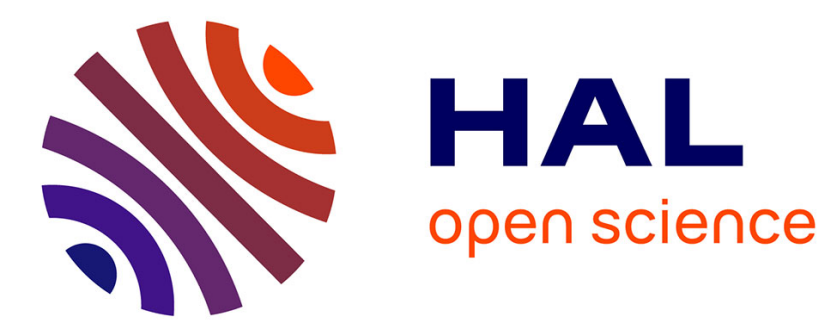

\title{
Channel segregation during columnar solidification: Relation between mushy zone instability and mush permeability
}

Alok Kumar, Miha Založnik, Hervé Combeau, Gérard Lesoult, Arvind Kumar

\section{- To cite this version:}

Alok Kumar, Miha Založnik, Hervé Combeau, Gérard Lesoult, Arvind Kumar. Channel segregation during columnar solidification: Relation between mushy zone instability and mush permeability. International Journal of Heat and Mass Transfer, 2021, 164, pp.120602. 10.1016/j.ijheatmasstransfer.2020.120602 . hal-03087035

\section{HAL Id: hal-03087035 \\ https://hal.science/hal-03087035}

Submitted on 23 Dec 2020

HAL is a multi-disciplinary open access archive for the deposit and dissemination of scientific research documents, whether they are published or not. The documents may come from teaching and research institutions in France or abroad, or from public or private research centers.
L'archive ouverte pluridisciplinaire HAL, est destinée au dépôt et à la diffusion de documents scientifiques de niveau recherche, publiés ou non, émanant des établissements d'enseignement et de recherche français ou étrangers, des laboratoires publics ou privés. 


\section{Channel Segregation during Columnar Solidification: Relation between Mushy Zone Instability and Mush Permeability}

Alok Kumar ${ }^{1}$, Miha Založnik ${ }^{2}$, Hervé Combeau ${ }^{3}$, Gérard Lesoult ${ }^{4}$, Arvind Kumar ${ }^{5, *}$

${ }^{1}$ Department of Mechanical Engineering, Indian Institute of Technology Kanpur, Kanpur 208016, India.

alokkr@,iitk.ac.in

${ }^{2}$ Université de Lorraine, CNRS, IJL, Nancy F-54000, France.

miha.zaloznik@univ-lorraine.fr

${ }^{3}$ Université de Lorraine, CNRS, IJL, Nancy F-54000, France.

herve.combeau@univ-lorraine.fr

${ }^{4}$ THERSOL Conseil, Consulting Company, 44300 Nantes, France; formerly, Ecole des Mines, 54042 Nancy, France.

gerard.lesoult@,orange.fr

${ }^{5}$ Department of Mechanical Engineering, Indian Institute of Technology Kanpur, Kanpur 208016, India.

arvindkr@iitk.ac.in

Corresponding author:

*Arvind Kumar - arvindkr@iitk.ac.in 


\begin{abstract}
A model of mushy zone instability is developed for characterization and prediction of channel segregation in castings. The model highlights the connection of the mushy zone instability with the mush permeability. A new criterion for amplification of the mush instability is derived, which depends on the interdendritic velocity, the isotherm velocity, the temperature gradient, and explicitly on the mush permeability. The capability of the instability criterion in the characterization of channel segregates is illustrated by comparing the estimated possible channel locations with that of numerically simulated channel segregations in a benchmark test case of solidification of $\mathrm{Sn}-\mathrm{Pb}$ alloy. An Opensource CFD software OpenFOAM is used to simulate the solidification of $\mathrm{Sn}-\mathrm{Pb}$ alloy in a side-cooled rectangular cavity. The new instability criterion very well characterizes the channel segregates shown in the numerical simulations. The near-liquidus part of the mushy region is more prone to the initiation of instability, which can initiate the formation of channel segregates in castings. Permeability and its derivative with respect to the liquid fraction in the outer part of mushy zone (liquid fraction more than 0.9 ) plays a key role in the amplification of this instability that can be responsible for the development and the formation of channel segregates. The locations of channel segregates estimated by the new instability model are also compared with those with a remelting criterion, and it has been noticed that the remelting criterion severely under characterizes these defects (e.g., their number and length). We noticed that local remelting might not be necessary for the initiation of a channel; some destabilization of the mushy zone due to local instability could be sufficient.
\end{abstract}

Keywords: Channel segregation; Casting; Instability; Mushy zone permeability; Solidification; Remelting. 


\section{List of symbols}

$C \quad$ average mass fraction of solute $(\mathrm{Pb}), \mathrm{wt} \%$

$C_{0} \quad$ initial mass fraction of solute $(\mathrm{Pb})$ in the alloy, wt \%

$d_{2} \quad$ secondary dendritic arm spacing, $\mathrm{m}$

$g_{l} \quad$ volume fraction of liquid

$\delta g_{l} \quad$ small perturbation in liquid fraction

$\vec{g}_{r} \quad$ gravity vector, $\mathrm{m} \mathrm{s}^{-2}$

NIC numerical value of the New instability criterion, $\mathrm{K} \mathrm{s}^{-1}$

$F R C$ numerical value of the Fleming's remelting criterion, $\mathrm{K} \mathrm{s}^{-1}$

$K \quad$ mush permeability, $\mathrm{m}^{2}$

$k_{p} \quad$ binary partition coefficient

$m \quad$ liquidus slope, $\mathrm{K}$ wt $\%{ }^{-1}$

$t$ time, $\mathrm{s}$

$T \quad$ temperature, $\mathrm{K}$

$\nabla T \quad$ temperature gradient, $\mathrm{K} \mathrm{m}^{-1}$

$\vec{v} \quad$ superficial average velocity, $\mathrm{m} \mathrm{s}^{-1}$

$\vec{v}_{l} \quad$ intrinsic liquid phase velocity, $\mathrm{m} \mathrm{s}^{-1}$

$\delta \vec{v}_{l} \quad$ small perturbation in intrinsic liquid phase velocity, $\mathrm{m} \mathrm{s}^{-1}$

$\vec{v}_{T} \quad$ isotherm velocity, $\mathrm{m} \mathrm{s}^{-1}$

$X, Y$ coordinate axes, $\mathrm{m}$

\section{Greek Symbols}

$\beta_{\mathrm{T}} \quad$ thermal expansion coefficient, $\mathrm{K}^{-1}$

$\beta_{\mathrm{C}} \quad$ solutal expansion coefficient, wt $\%^{-1}$

$\mu \quad$ dynamic viscosity, $\mathrm{kg} \mathrm{m}^{-1} \mathrm{~s}^{-1}$

$\rho \quad$ mass density, $\mathrm{kg} \mathrm{m}^{-3}$

\section{Subscripts}

0 reference

1 liquid

$\mathrm{m} \quad$ melting point for a pure substance

s solid

\section{Introduction}

Defects in casting processes depend critically on the permeability associated with the mushy zone that influences the interdendritic liquid flow [1]. Fluid flow in the mushy zone causes macrosegregation in the castings by redistributing the segregated solute elements [2-10] and in some cases, also forms channel segregates [8-21]. The mushy zone is represented as a saturated porous medium with varying permeability [20-23]. Permeability in the mushy zone, which for the simplest model is a function of the liquid fraction and the dendritic arm spacing (DAS), varies over a wide range of magnitude for liquid fraction varying from 1 to 0 [1, 2023]. A small variation in the liquid fraction can result in a large variation of permeability, which can significantly influence the flow in the mushy region [1, 20-23]. Permeability is the principal parameter of the Darcy term, which is used to describe the hydrodynamic drag of 
the porous mush in the momentum conservation equation [20-24]. Therefore, the mushy zone permeability becomes one of the parameters that have an essential effect on the nature and the extent of segregation as it determines the intensity of the interdendritic liquid flow [2031].

Channel segregations in castings represent a severe form of the defect since the composition and crystalline structure of the solid within the channels differ significantly from those of the nearby regions [20-21]. Further, the scale of channel segregations influences the homogenization of the castings and its extent in the casting can severely affect their quality and mechanical properties [20-21]. In casting, they appear as long, narrow trails aligned in some preferred direction, with a solute concentration greater than that of the surrounding regions [20-21]. The channel segregates can form by an instability in the mushy zone, which is caused by the interdendritic fluid flow and in some cases, by the localized remelting in some portions of the mush/melt interface [8, 12-13, 20, 27-29]. The instability in the mushy zone leads to perturbations of the growing columnar structure, causing instability of the growth front. It in turn, leads to instability of the segregation profile leading to the formation of channel segregates [12, 20, 28-29]. Conditions favorable for the growth of channel segregates in the presence of a small defect are derived in [29], where it was suggested that the presence of the small defect forms channel segregates that grow much more readily than in a homogeneous dendritic medium. It is often stated that the mushy zone flow plays an essential role on the formation of channel segregations [13, 20, 28-29]. However, a criterion for the amplification of the mushy zone instability explicitly based on the local mushy zone parameters (such as its permeability) is not adequately addressed in literature. Establishment of such a physics-based criterion for the amplification of the mushy zone instability is essential for understanding the parameters governing such instabilities, thereby leading to an accurate prediction of the channel segregates and possible control of their occurrence in castings.

In this study, a model for the amplification of perturbations in the mushy zone leading to mush instability is developed. The model depicts the dependence of instability on the interdendritic velocity, the isotherm velocity and the temperature gradient. An attempt is made to explicitly relate the criterion for amplification of the mushy zone instability to the characteristic of the mushy zone, i.e., the mush permeability. The conditions favorable for amplification of these instabilities are highlighted based on the criterion derived. To illustrate the capability of the instability criterion in the characterization of channel segregates in casting, the estimated possible channel locations from the developed criterion are compared 
with the channel segregations obtained from numerical simulation using a fully coupled model of heat, mass, solute and momentum transport during columnar solidification [3]. The model assumes a fixed solid phase and full equilibrium in the liquid at the microscopic scale. Finally, it is shown that channel formation can be studied in a new manner thanks to the new mushy zone instability model. We demonstrate that a channel starts to develop due to the amplification of a small perturbation in liquid fraction if a local condition is satisfied. Further, the prediction of channel segregates using the new mushy zone instability model and the existing remelting based channel segregation criterion are compared and discussed.

\section{Development of the mushy zone instability criterion}

Fig. 1 shows schematically a liquid-solid mushy region in a rectangular cavity solidifying from the left wall. Liquid near the roots of the dendrites is highly segregated, i.e., enriched in solute, and this is shown by the darker shading (see Fig. 1a). In the dendritic columnar mushy zone, the average distance between the side branches, i.e., the secondary dendritic arm spacing $\left(d_{2}\right)$ is used as the characteristic length scale of the porous structure in the permeability model (Fig. 1b). As an example, a typical width of the mushy zone is of the order of $10 \mathrm{~mm}$. Spacing of dendrite arms in such a mushy zone would be the order of $\sim 0.01-0.1 \mathrm{~mm}$, as shown in Fig. 1(b) [28]. The scale of the REV used for the description of such a mushy zone is of the order of few $d_{2}$ (see Fig. 1c). The channel segregates form due to the perturbation in the liquid fraction field (shown by isolines of the liquid fraction field in Fig 1d) near the high- $g_{l}$ region of the mushy zone as the solidification progresses (see Fig. 1d). The length scale of the channel type segregation is approximately $1-10 \mathrm{~mm}$. We can precise the length of a channel is $10 \mathrm{~mm}$ while the width is $1 \mathrm{~mm}$. These dimensions are at least 10 times larger than the characteristic size of the porous structure, $d_{2}(0.1 \mathrm{~mm})$. The channel width is of the same order of magnitude as the REV size. The analysis presented in this work is conducted at the scale of the REV whose size is in the order of few $d_{2}$. It is important to notice that the only characteristic size given as an input to the averaged model is that used for the permeability, i.e., $d_{2}$. What can be also said is that the channel width we obtained from the simulation results is of the same order of magnitude as the REV dimension. The analysis conducted by Mehrabian et al. [28] was exactly at the same scale as in the present work. 


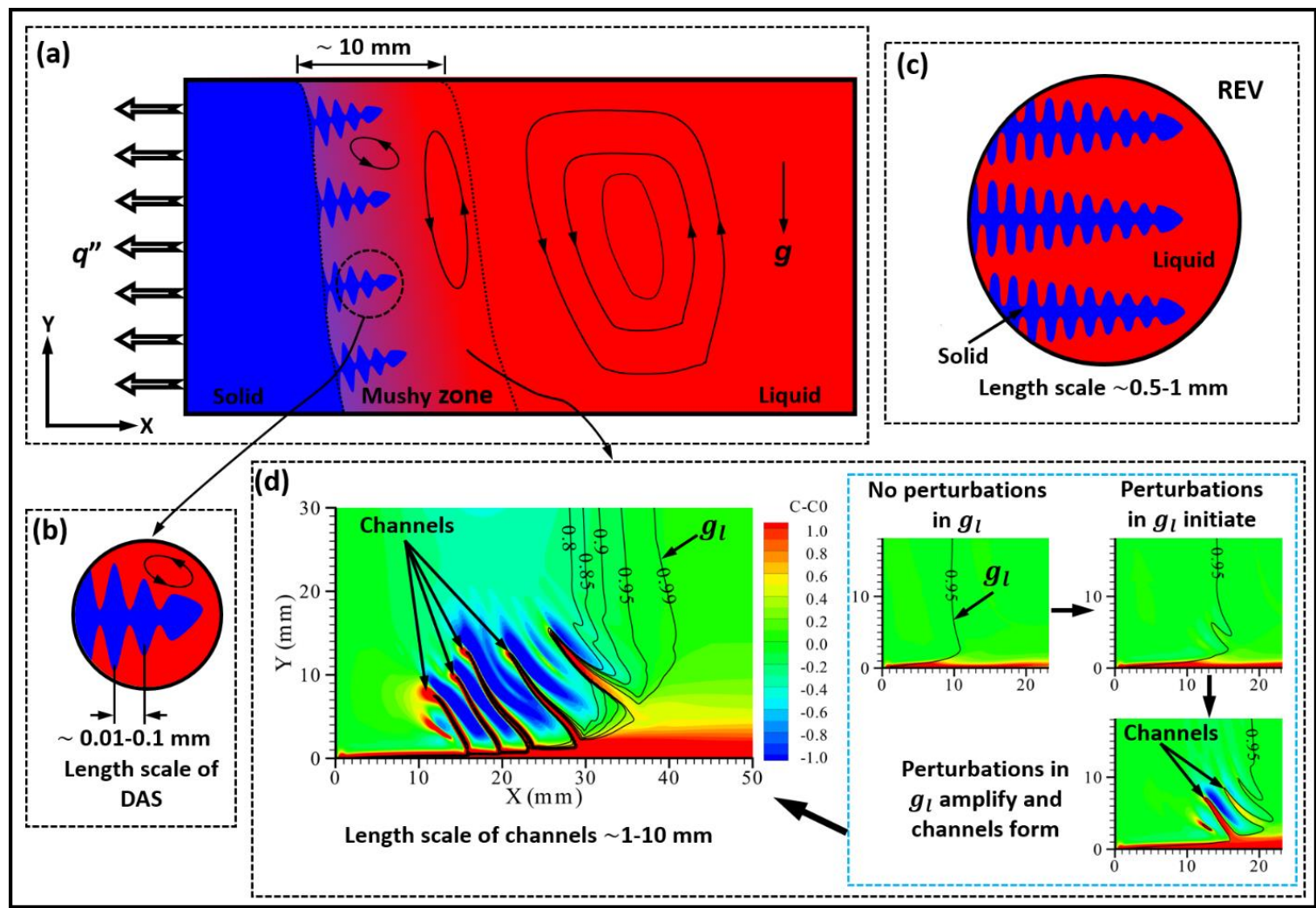

Figure 1: Schematic illustrating the physical scales and the formation of channel segregates phenomena during columnar solidification (a) system (macroscopic) scale (dendrites in the mushy zone are exaggerated, they will be seen at high magnification), (b) grain scale, (c) representative elementary volume (REV), (d) formation of channel segregates (isolines in black color show the liquid fraction field).

Assuming dendritic columnar solidification with rigid solid dendrites, constant physical properties of the mixture and Boussinesq approximation, the momentum conservation for the liquid phase using one-domain and volume averaging modeling approach is given as follows [32]:

$$
\begin{aligned}
\rho \frac{\partial\left(g_{l} \vec{v}_{l}\right)}{\partial t}+\rho \nabla \cdot\left(g_{l} \vec{v}_{l} \vec{v}_{l}\right)= & -g_{l} \nabla \mathrm{p}+g_{l} \mu \nabla^{2} \vec{v}_{l}-g_{l}{ }^{2} \frac{\mu}{K} \vec{v}_{l} \\
& +\rho_{0} g_{l} \vec{g}_{r}\left[\beta_{T}\left(T-T_{0}\right)+\beta_{C}\left(C_{l}-C_{0}\right)\right]
\end{aligned}
$$

The mushy zone is considered as a porous medium, of permeability $K$, saturated with liquid. The third term on R.H.S of the Eq. (1) accounts for the drag force of the solid skeleton on the interdendritic liquid $[2-4,7,10]$. To assess the role of permeability on the instability in the mushy zone, we consider fluid flow in this region. In the mushy zone, the inertial and viscous terms of Eq. (1) can be neglected and it reduces to the Darcy equation [28].

$$
\frac{\mu}{K\left(g_{l}\right)} g_{l} \vec{v}_{l}=-\nabla \mathrm{p}+\rho_{0} \vec{g}_{r}\left[\beta_{T}\left(T-T_{0}\right)+\beta_{C}\left(C_{l}-C_{0}\right)\right]
$$


For the simplest mushy zone permeability model, $K$ is a function of $g_{l}$ and the characteristic size in the microstructure (secondary dendritic arm spacing, $d_{2}-$ a constant value of $d_{2}$ is assumed in this study). If locally, we perturb the liquid fraction (porosity) field by $\delta g_{l}$, one observes a corresponding perturbation $\delta \vec{v}_{l}$ caused in the velocity field.

$$
\begin{aligned}
\frac{\mu}{K\left(g_{l}+\delta g_{l}\right)}[ & \left.\left(g_{l}+\delta g_{l}\right)\left(\vec{v}_{l}+\delta \vec{v}_{l}\right)\right] \\
& =-\nabla \mathrm{p}+\rho_{0} \vec{g}_{r}\left[\beta_{T}\left(T-T_{0}\right)+\beta_{C}\left(C_{l}-C_{0}\right)\right]
\end{aligned}
$$

One can notice that a perturbation in liquid can occur for different reasons like instability in the fluid flow. The analysis that we present corresponds to a classical linear perturbation analysis in which the goal is to determine conditions corresponding to an amplification of the instability. If it is possible to get such conditions, this analysis will introduce a new way to understand phenomena like channel formation as we will illustrate later.

The perturbations in the liquid fraction and the velocity field can of course trigger further perturbations in pressure, temperature and concentration fields. In the following analysis, these perturbations are neglected. It is based on the following assumptions:

- We assume that the temperature field in the mushy zone is mainly controlled by diffusive heat transfer. Therefore, the influence of a flow perturbation on the temperature field is negligible.

- We further assume that the time scale of the evolution of perturbation is large with respect to the time scale of solute diffusion at the scale of the secondary dendrite arm spacing. Therefore, we can assume that the local liquid composition in the mushy zone is at thermodynamic equilibrium and closely follows the temperature field. Similarly, the perturbation of liquid concentration can thus be considered negligible.

- The strongest assumption is that of negligible perturbation of the pressure field, its validity is shown in the results.

In Eq. (3), $K\left(g_{l}\right)$ will become $K\left(g_{l}+\delta g_{l}\right)$ after the perturbation. On subtracting Eq. (2) from Eq. (3) one gets

$$
\frac{\mu}{K\left(g_{l}+\delta g_{l}\right)}\left[\left(g_{l}+\delta g_{l}\right)\left(\vec{v}_{l}+\delta \vec{v}_{l}\right)\right]=-\frac{\mu}{K} g_{l} \vec{v}_{l}
$$

which can be rearranged to

$$
\begin{gathered}
\vec{v}_{l}+\delta \vec{v}_{l}=\vec{v}_{l} \frac{K\left(g_{l}+\delta g_{l}\right)}{K} \frac{g_{l}}{\left(g_{l}+\delta g_{l}\right)} \\
\vec{v}_{l}+\delta \vec{v}_{l}=\left[K\left(g_{l}\right)+\frac{d K}{d g_{l}} \delta g_{l}\right] \frac{g_{l} \vec{v}_{l}}{K}\left[\frac{1}{g_{l}}\left(1+\frac{\delta g_{l}}{g_{l}}\right)^{-1}\right]
\end{gathered}
$$


Since the perturbation $\delta g_{l}$ is small, the second and higher order terms of $\frac{\delta g_{l}}{g_{l}}$ will be very small and hence can be neglected while expanding Eq. (5b) as

$$
\vec{v}_{l}+\delta \vec{v}_{l}=\left[K\left(g_{l}\right)+\frac{d K}{d g_{l}} \delta g_{l}\right] \frac{g_{l} \vec{v}_{l}}{K}\left[\frac{1}{g_{l}}\left(1-\frac{\delta g_{l}}{g_{l}}\right)\right]
$$

Again, while expanding Eq. (5c) the terms containing the square of $\delta g_{l}$ (as they will be small) can be neglected, which give us

$$
\begin{gathered}
\vec{v}_{l}+\delta \vec{v}_{l}=\vec{v}_{l}-\frac{\vec{v}_{l}}{g_{l}} \delta g_{l}+\frac{\vec{v}_{l}}{K} \frac{d K}{d g_{l}} \delta g_{l} \\
\delta \vec{v}_{l}=\vec{v}_{l}\left[\frac{1}{K} \frac{d K}{d g_{l}}-\frac{1}{g_{l}}\right] \delta g_{l}
\end{gathered}
$$

Equation (6b) suggests that the perturbation in velocity $\delta \vec{v}_{l}$ is proportional to the perturbation in liquid fraction $\delta g_{l}$ and the velocity $\vec{v}_{l}$, which suggests that the higher the interdendritic velocity, the higher will be the extent of perturbation. It is also interesting to note that $\delta \vec{v}_{l}$ depends on a bracketed term $\left[\frac{1}{K} \frac{d K}{d g_{l}}-\frac{1}{g_{l}}\right]$ which consists of permeability and its derivative with respect to $g_{l}$. To understand whether the perturbation in $g_{l}$ (i.e., $\delta g_{l}$ ) will amplify or dampen with time, one needs to evaluate the sign of $\frac{\partial\left(\delta g_{l}\right)}{\partial t}$. It needs consideration of the coupling of phase change with the transport of heat and solute.

We consider the averaged solute conservation equation for the solid and liquid phases and assume infinite diffusion in the liquid phase and zero diffusion in the solid phase (Scheil's assumption) at the scale of the secondary dendrite arms (microscopic scale) [28]. The averaged solute conservation equation can be expressed as [28]

$$
\frac{\partial\left(g_{l} C_{l}\right)}{\partial t}+C_{s}^{*} \frac{\partial g_{s}}{\partial t}+g_{l} \vec{v}_{l} \cdot \nabla C_{l}=0
$$

In Eq. (7), $C_{l}$ is the volume-averaged concentration in the liquid phase and $C_{S}^{*}$ is the concentration in the solid phase at the solid-liquid interface. The liquid phase is at the thermodynamic equilibrium composition due to infinite diffusion, thus we can express the temperature by $T=T_{m}+m C_{l}$, where $T_{m}$ is the melting temperature of the pure solvent and $m$ is the liquidus slope. The solid-liquid interface is at thermodynamic equilibrium, and thus $C_{s}^{*}=k_{p} C_{l}$, where $k_{p}$ is the binary partition coefficient. Eq. (7) transforms to

$$
g_{l} \frac{1}{m} \frac{\partial T}{\partial t}+\left(1-k_{p}\right) C_{l} \frac{\partial g_{l}}{\partial t}+\frac{1}{m} g_{l} \vec{v}_{l} \cdot \nabla T=0
$$

Expressing $\frac{\partial T}{\partial t}=-\vec{v}_{T} \cdot \nabla T$ (where $\vec{v}_{T}$ is the velocity of the isotherm), Eq. (8) becomes 


$$
\left(1-k_{p}\right) C_{l} \frac{\partial g_{l}}{\partial t}+\frac{1}{m} g_{l}\left(\vec{v}_{l}-\vec{v}_{T}\right) \cdot \nabla T=0
$$

We again impose an infinitesimal perturbation $\delta g_{l}$ in $g_{l}$ in Eq. (9) which causes an infinitesimal perturbation $\delta \vec{v}_{l}$ in $\vec{v}_{l}$. As considered earlier the influence of this perturbation on $\vec{v}_{T}, \nabla T$ and $C_{l}$ is assumed to be negligible. The perturbed form of Eq. (9) becomes

$$
\left(g_{l}+\delta g_{l}\right) \frac{1}{m}\left[\left(\vec{v}_{l}+\delta \vec{v}_{l}\right)-\vec{v}_{T}\right] \cdot \nabla T+\left(1-k_{p}\right) C_{l} \frac{\partial\left(g_{l}+\delta g_{l}\right)}{\partial t}=0
$$

Subtracting Eq. (9) from Eq. (10) and keeping only the first-order term of $\delta g_{l}$ (as $\delta g_{l}$ is small), we obtain

$$
\frac{1}{m} g_{l} \delta \vec{v}_{l} \cdot \nabla T+\frac{1}{m} \delta g_{l}\left[\vec{v}_{l}-\vec{v}_{T}\right] \cdot \nabla T+\left(1-k_{p}\right) C_{l} \frac{\partial\left(\delta g_{l}\right)}{\partial t}=0
$$

Using the relation for $\delta \vec{v}_{l}$ from Eq. (6b), we get

$$
\begin{gathered}
\frac{1}{m} g_{l} \vec{v}_{l}\left[\frac{1}{K} \frac{d K}{d g_{l}}-\frac{1}{g_{l}}\right] \delta g_{l} \cdot \nabla T+\frac{1}{m} \delta g_{l}\left[\vec{v}_{l}-\vec{v}_{T}\right] \cdot \nabla T+\left(1-k_{p}\right) C_{l} \frac{\partial\left(\delta g_{l}\right)}{\partial t}=0 \\
\frac{1}{m}\left[g_{l} \vec{v}_{l} \frac{1}{K} \frac{d K}{d g_{l}}-\vec{v}_{T}\right] \cdot \nabla T \delta g_{l}+\left(1-k_{p}\right) C_{l} \frac{\partial\left(\delta g_{l}\right)}{\partial t}=0
\end{gathered}
$$

Rearrangement of Eq. (12b) gives

$$
\frac{\partial\left(\delta g_{l}\right)}{\partial t}=-\frac{1}{m\left(1-k_{p}\right) C_{l}}\left[g_{l} \vec{v}_{l} \frac{1}{K} \frac{d K}{d g_{l}}-\vec{v}_{T}\right] \cdot \nabla T \delta g_{l}
$$

For $k_{p}$ value less than one and negative value of the slope $m$, it gives a condition for perturbation $\delta g_{l}$ to amplify with time as

$$
\frac{\partial\left(\delta g_{l}\right)}{\partial t}>0 \text { if } \vec{v}_{l} \cdot \nabla T>\frac{K}{g_{l}}\left(\frac{d K}{d g_{l}}\right)^{-1}\left(\vec{v}_{T} \cdot \nabla T\right)
$$

It may be noted that the new criterion is derived in terms of amplification of the local perturbations in the mushy zone i.e., $\frac{\partial\left(\delta g_{l}\right)}{\partial t}>0$, which is different from a remelting criterion i.e., $\frac{\partial g_{l}}{\partial t}>0$. The derived criterion for amplification of perturbation involves a local permeability term (and hence the local liquid fraction) which makes it different from the existing remelting criterion such as, Flemings' criterion of remelting, $\vec{v}_{l} \cdot \nabla T>\vec{v}_{T} \cdot \nabla T$ [28]. From Eq. (13) it can be seen that the mush instability depends on the interdendritic velocity, the isotherm velocity and the temperature gradient. Also, it explicitly depends on the dynamically changing characteristic of the mushy zone during solidification i.e., on the permeability. It is evident that for a given cooling rate the two favorable conditions for 
amplification of perturbation are a higher interdendritic velocity $\left(v_{l}\right)$ in the direction parallel to $\nabla T$ and/ or a lower value of $\frac{K}{g_{l}}\left(\frac{d K}{d g_{l}}\right)^{-1}$.

A widely used approach in modeling the mushy zone permeability is to use the BlakeKozeny permeability model [20-23, 31, 33], which is given as

$$
K=\frac{d_{2}^{2} g_{l}^{3}}{180\left(1-g_{l}\right)^{2}}
$$

In the dendritic columnar mushy zone, the interdendritic characteristic arm spacing is used to describe the mushy zone permeability. The average distance between the side branches i.e., the secondary dendritic arm spacing $\left(d_{2}\right)$ is used as the interdendritic characteristic arm spacing in the permeability model. The above expression is very schematic and a more realistic description, accounting for the microstructure of the dendrites, would be necessary. However, this challenging and very important point is out of the scope of the present study. Since our main objective is to discuss the relationship between the mushy zone instability and the mush permeability, a simplified expression for mushy zone permeability law (BlakeKozeny permeability model) is used. It is important to notice at this stage that as we use the Scheil's assumption, the characteristic size $d_{2}$ introduced in equation (14) is the only characteristic size appearing in the whole set of equations of the model. Which means in other words that the size of the REV used for the averaging procedure is in the order of magnitude of $d_{2}$.

Table 1 shows the expression of $\frac{K}{g_{l}}\left(\frac{d K}{d g_{l}}\right)^{-1}$ function for the Blake-Kozeny permeability law considered in the present study. The variation of normalized permeability $\left(K / d_{2}^{2}\right)$ with the liquid fraction is plotted in Fig. 2a. In high- $g_{l}$ regions, the variation of $K$ is very sharp. We plot in Fig. $2 \mathrm{~b}$ the dependence of $\frac{K}{g_{l}}\left(\frac{d K}{d g_{l}}\right)^{-1}$ on $g_{l}$ which shows that $\frac{K}{g_{l}}\left(\frac{d K}{d g_{l}}\right)^{-1}$ is always lower than unity. Therefore, according to Eq. (13), any perturbation in $g_{l}$ can amplify even before the remelting criterion $\vec{v}_{l} \cdot \nabla T>\vec{v}_{T} \cdot \nabla T$ [28] is satisfied because of always lower than unity value of $\frac{K}{g_{l}}\left(\frac{d K}{d g_{l}}\right)^{-1}$ term. Further, it can be noted that in the high- $g_{l}$ regions the value of $\frac{K}{g_{l}}\left(\frac{d K}{d g_{l}}\right)^{-1}$ is very low which makes amplification of perturbation in $g_{l}$ more sensitive in the high- $g_{l}$ regions of the mushy zone. the result presented in Fig. $2 \mathrm{~b}$ suggests, as also pointed out in [13, 27, 29], that the part of mushy region near the liquidus is more prone to the initiation of the instability. 
Table 1: Normalized permeability and $\frac{K}{g_{l}}\left(\frac{d K}{d g_{l}}\right)^{-1}$ function.

\begin{tabular}{|c|c|}
\hline \multicolumn{2}{|c|}{ Blake-Kozeny permeability model } \\
\hline$\frac{K}{d_{2}^{2}}$ & $\frac{g_{l}^{3}}{180\left(1-g_{l}\right)^{2}}$ \\
\hline$\frac{K}{g_{l}}\left(\frac{d K}{d g_{l}}\right)^{-1}$ & $\frac{1-g_{l}}{3-g_{l}}$ \\
\hline
\end{tabular}

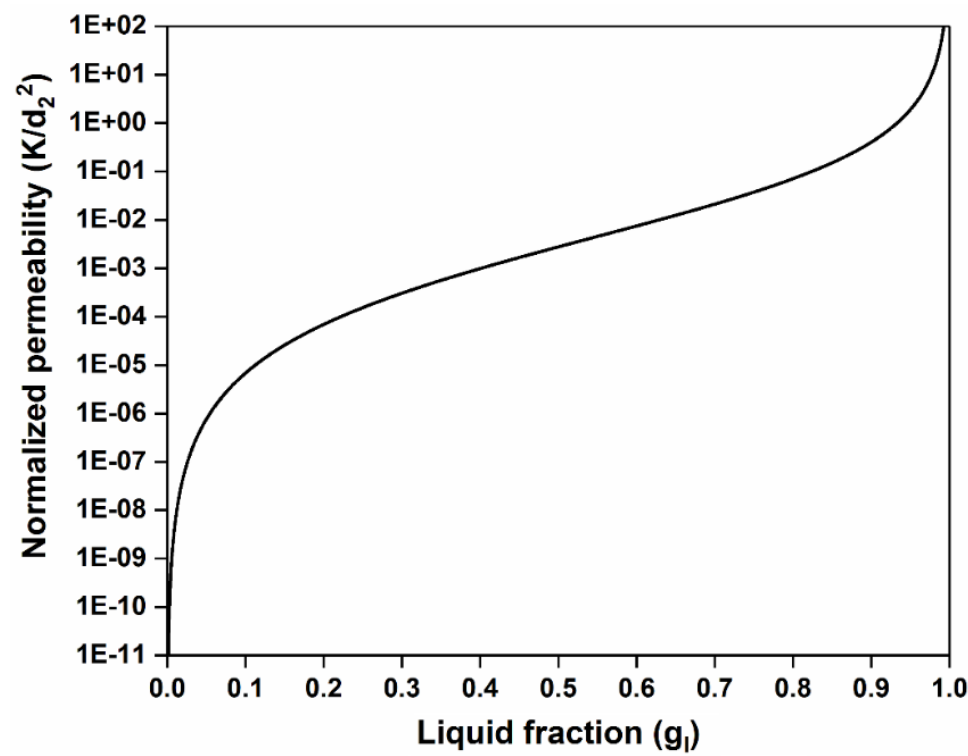

(a)

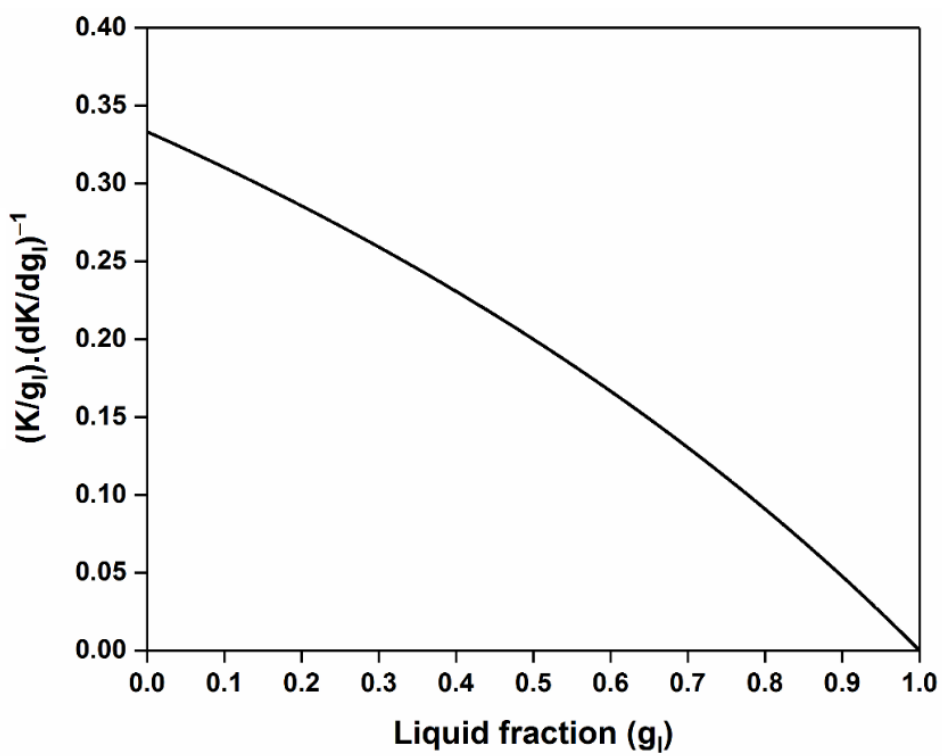

(b)

Figure 2: Variation of (a) normalized permeability and (b) $\frac{K}{g_{l}}\left(\frac{d K}{d g_{l}}\right)^{-1}$ with liquid fraction.

\section{Results and discussion}


To illustrate the application of the instability criterion for understanding the development of channel segregations, we applied this criterion to a case study where channels develop. We show that the estimated channel locations from the developed criterion closely coincide with the numerically simulated channels. The case study we have chosen corresponds to a benchmark test case of $\mathrm{Sn}-\mathrm{Pb}$ alloy in a two-dimensional rectangular cavity. It is worth to mention that for this benchmark case, channel type of segregations were reported experimentally [34-36] and numerically [1, 10, 20]. Subsequently, with the help of the mushy zone instability model developed, the relation between the mush instability and the mush permeability is discussed.

\subsection{Simulation details}

We consider the solidification of a binary Sn-5 wt \% Pb alloy, which corresponds to the wellknown benchmark physical model of Hebditch and Hunt [34] and the numerical study of Ahmad et al. [10]. The cavity is cooled from the left side and the remaining three sides are thermally insulated (Figure 3). The initial temperature $T_{0}=226{ }^{\circ} \mathrm{C}$ corresponds to an initial superheat of $0.43{ }^{\circ} \mathrm{C}$. For the considered alloy $(\mathrm{Sn}-5$ wt $\% \mathrm{~Pb})$, the thermal and solutal buoyancy forces are cooperating as the heavier solute $(\mathrm{Pb})$ is rejected into the liquid upon solidification. This thermosolutal configuration tends to create a counter-clockwise flow as schematically shown in Figure 3. To simulate the solidification of $\mathrm{Sn}-\mathrm{Pb}$ alloy in a sidecooled two-dimensional rectangular cavity, a finite volume solver is developed in OpenFOAM using a macroscopic model based on continuum formulation [3]. In this computational model, assumptions such as laminar flow, Newtonian behavior of the liquid melt, saturated mixture conditions, local thermodynamic and local constitutional equilibrium are made. A more detailed discussion about the assumptions made in the present model can be found in [3]. The initial and boundary conditions used in the present simulation are taken from the previous studies reported in the literature $[1,10]$. The thermophysical property data and parameters used in the computations are provided in Table $2[1,10]$.

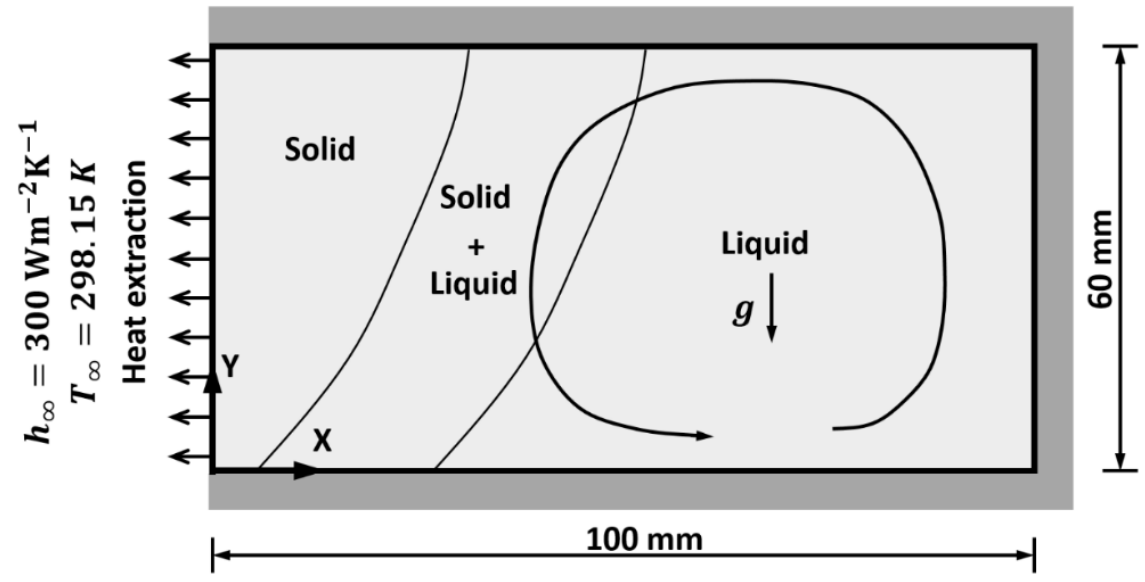


Figure 3: Schematic representation of the computational domain for solidification in a 2D rectangular cavity.

Table 2: Thermophysical data and parameters used in the simulation $[1,10]$.

\begin{tabular}{|c|c|}
\hline Parameter & Sn-5 wt \% Pb \\
\hline \multicolumn{2}{|l|}{ Phase diagram } \\
\hline Initial mass fraction, wt $\% \mathrm{~Pb}$ & 5.0 \\
\hline Melting temperature, $\mathrm{K}$ & 505.15 \\
\hline Eutectic temperature, $\mathrm{K}$ & 456.15 \\
\hline Eutectic mass fraction, wt $\% \mathrm{~Pb}$ & 38.1 \\
\hline Liquidus slope, $\mathrm{K}$ wt $\%^{-1}$ & -1.286 \\
\hline Partition coefficient & 0.0656 \\
\hline \multicolumn{2}{|l|}{ Thermophysical data } \\
\hline Specific heat, $\mathrm{J} \mathrm{kg}^{-1} \mathrm{~K}^{-1}$ & 260.0 \\
\hline Thermal conductivity, $\mathrm{W} \mathrm{m}^{-1} \mathrm{~K}^{-1}$ & 55.0 \\
\hline Latent heat of fusion, $\mathrm{J} \mathrm{kg}^{-1}$ & 61000 \\
\hline Reference mass density, $\mathrm{kg} \mathrm{m}^{-3}$ & 7000.0 \\
\hline Reference temperature, $\mathrm{K}$ & 499.15 \\
\hline Thermal expansion coefficient, $\mathrm{K}^{-1}$ & $6.0 \times 10^{-5}$ \\
\hline Solutal expansion coefficient, wt $\%^{-1}$ & $-5.3 \times 10^{-2}$ \\
\hline Dynamic viscosity, $\mathrm{kg} \mathrm{m}^{-1} \mathrm{~s}^{-1}$ & $10^{-3}$ \\
\hline Secondary dendrite arm spacing, $\mu \mathrm{m}$ & 100.0 \\
\hline \multicolumn{2}{|l|}{ Computational parameters } \\
\hline Initial temperature, $\mathrm{K}$ & 499.15 \\
\hline Heat transfer coefficient, $\mathrm{W} \mathrm{m}^{-2} \mathrm{~K}^{-1}$ & 300.0 \\
\hline External temperature, $\mathrm{K}$ & 298.15 \\
\hline Dimension of the cavity, $\mathrm{m}(\mathrm{X} \times \mathrm{Y})$ & $0.1 \times 0.06$ \\
\hline
\end{tabular}

The mesh dependency of the solution has been tested by performing simulations with $50 \times 50$, $100 \times 100, \quad 150 \times 150,200 \times 200,300 \times 300,400 \times 400,500 \times 500$ and $600 \times 600$ grids. The evolution of overall macrosegregation for above grids is compared using the Global Segregation Index (GSI) parameter. The Global Segregation Index (GSI) is defined as follows $[1,20]$.

$$
G S I=\frac{1}{C_{0}}\left[\frac{1}{V_{\text {domain }}} \iiint_{V_{\text {domain }}}\left(C-C_{0}\right)^{2} d V\right]^{1 / 2}
$$

The mesh dependency test shows that a fully mesh independent solution for the prediction of channel segregation patterns are very difficult to achieve. Similar observations were also made and discussed in detail by Kumar et al. [20]. However, we observed that the global 
macrosegregation pattern was captured reasonably well using $500 \times 500$ grids with less than $\sim 1 \%$ of the difference in GSI obtained for $500 \times 500$ and $600 \times 600$ grids (see Fig. 4). Therefore, based on the mesh dependency test, $500 \times 500$ grids were chosen for the simulations in the present study, considering that it constitutes a good compromise between the accuracy in the channels prediction and the computational effort.

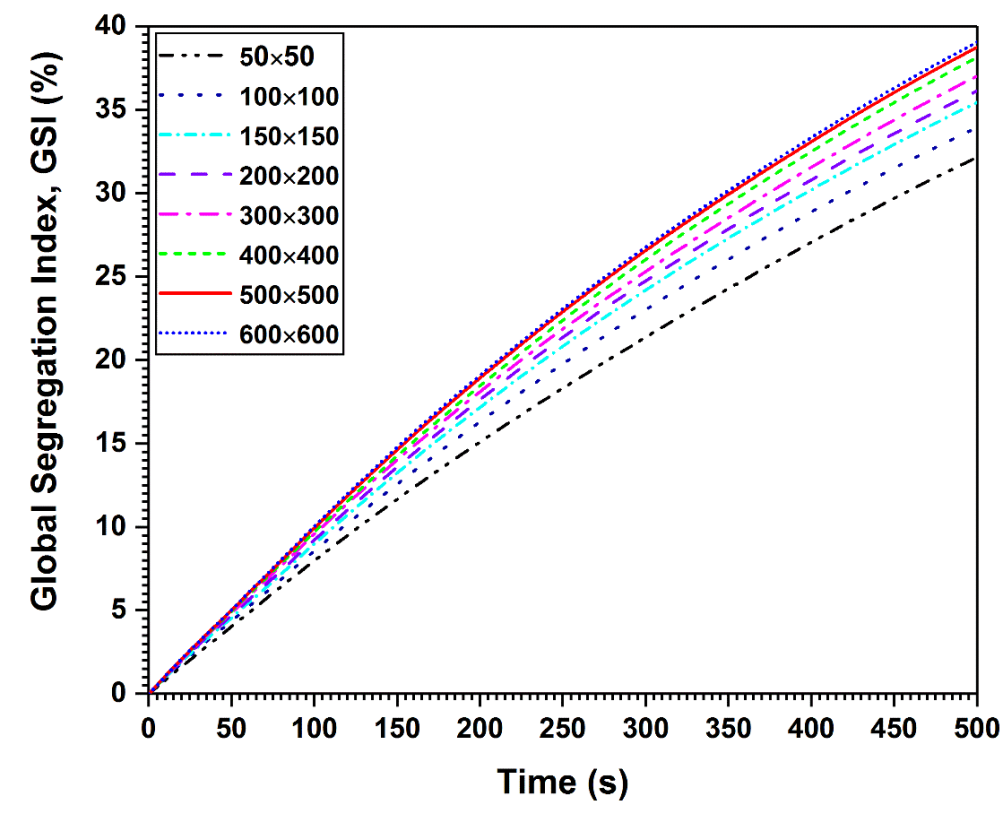

Figure 4: Transient evolution of global segregation index, GSI (\%) for different grids of $50 \times 50,100 \times 100,150 \times 150,200 \times 200,300 \times 300,400 \times 400,500 \times 500$, and $600 \times 600$.

\subsection{Validation of the solver}

The developed solver is validated with the experimental and the numerical studies reported in the literature [10,34]. The predicted final segregation maps obtained after complete solidification of $\mathrm{Sn}-5 \mathrm{wt} \% \mathrm{~Pb}$ alloy is compared and shown in Fig. 5. In this figure, the relative variations of composition are plotted along the horizontal axis for different heights: 5 , 25,35 , and $55 \mathrm{~mm}$ from the bottom wall of the cavity. The excellent agreement is found in the upper part of the cavity $(55 \mathrm{~mm})$, where the solidification starts first (negative segregation). The agreement is not much satisfactory near the bottom portion of cavity (5 $\mathrm{mm}$ ), where strong positive segregation is formed at the end of solidification. It might come from the freckling tendency and the shrinkage, which are not accounted for in the simulation. Overall, a good agreement witnessed between the present model and the experimental and numerical results reported in literature establishes the accuracy of the present model. 


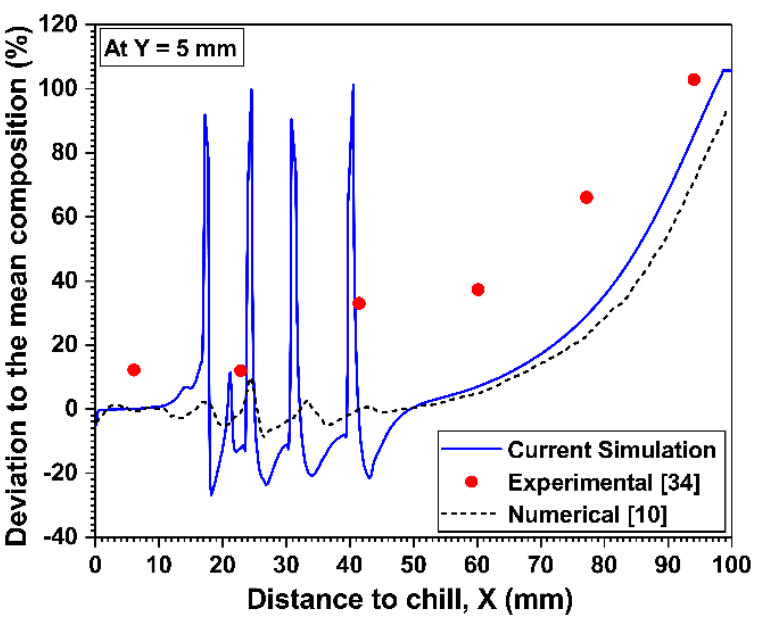

(a)

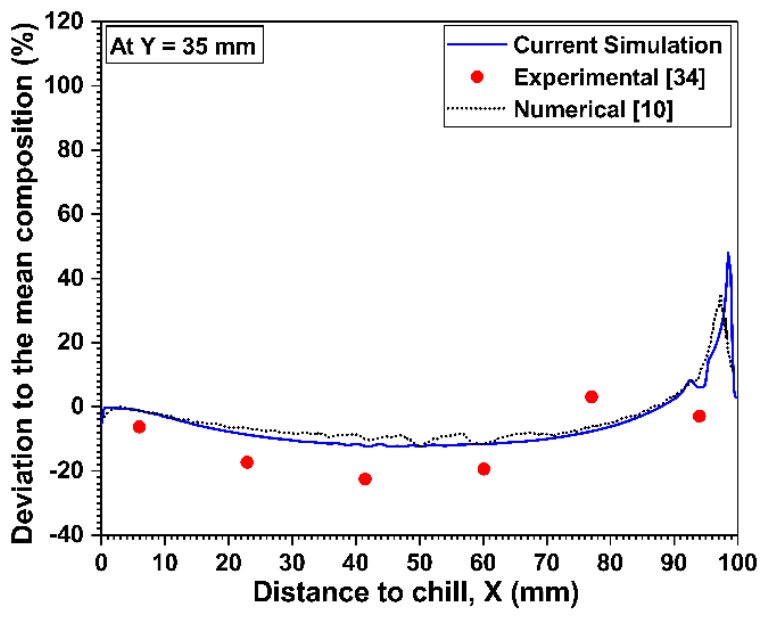

(c)

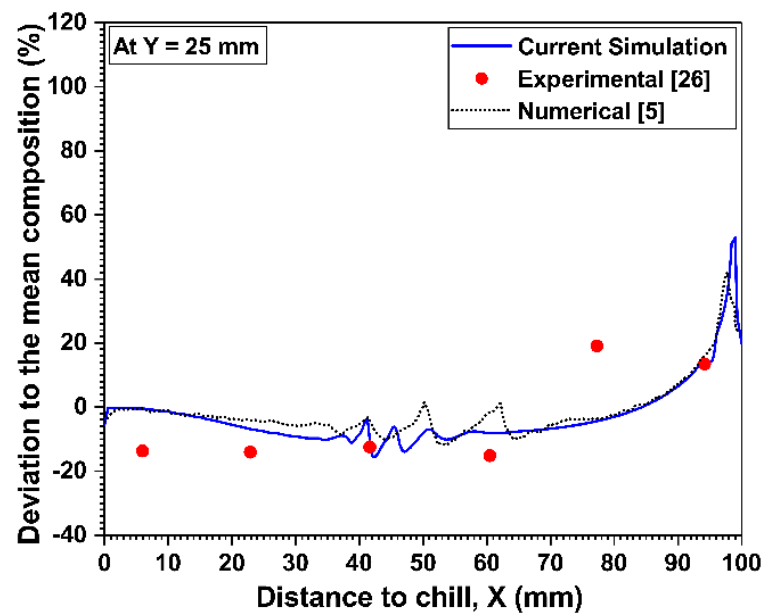

(b)

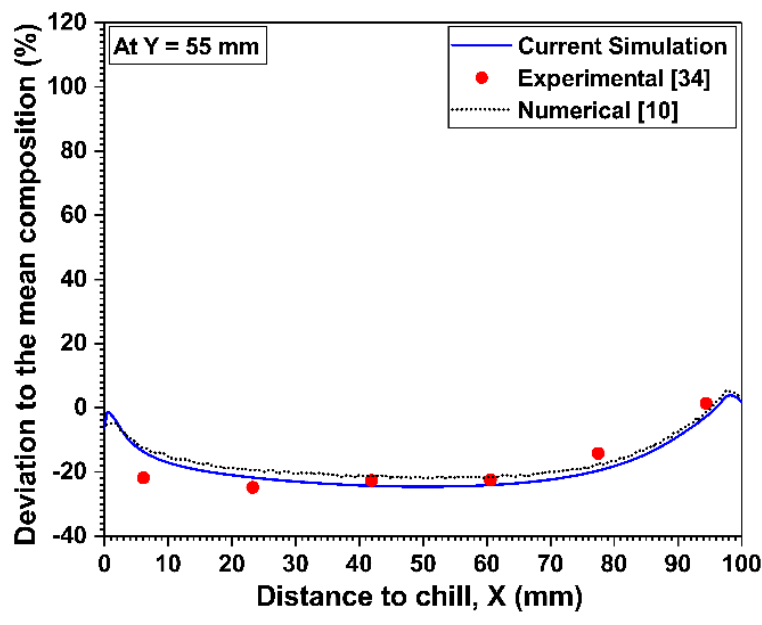

(d)

Figure 5: Variation of relative composition of $\mathrm{Sn}-5 \mathrm{wt} \% \mathrm{~Pb}$ alloy as a function of the distance to the cold wall at the end of solidification at different heights of the cavity: (a) 5 $\mathrm{mm}$, (b) $25 \mathrm{~mm}$, (c) $35 \mathrm{~mm}$, and (d) $55 \mathrm{~mm}$.

\subsection{Simulation results}

Figure 6 displays the segregation map, liquid fraction map, and flow pattern in the cavity at $t$ $=400 \mathrm{~s}$, when the structure of the channel segregates becomes quasi-stationary [20]. The segregation map has a positive macrosegregation in the area below the diagonal from the lower-left corner and negative above this diagonal (see Fig. 6a). The nature of segregation is classical with respect to the direction of liquid flow during solidification [10]. The dependence of segregation tendencies on the melt flow direction and the thermal extraction was elaborated in [11-12] according to $\partial C / \partial t=-g_{l} \vec{v}_{l} \cdot \nabla T / m$. In the present case, in the areas where positive macrosegregation is predicted, the liquid velocity is oriented to the temperature gradient such that $\vec{v}_{l} \cdot \nabla T$ is positive. It leads to a tendency to form a positive macrosegregation (note that the liquidus slope $m$ is negative for the alloy considered) [1112]. On the other hand, in the areas of negative macrosegregation, the liquid velocity is 
oriented to the temperature gradient such that $\vec{v}_{l} \cdot \nabla T$ is negative leading to a tendency of forming a negative macrosegregation.

We also notice some channel type segregates (horizontal and inclined) in the solidifying cavity. A horizontal channel segregate is found along the bottom of the cavity. It is estimated that this horizontal channel has the maximum mixture concentration whose value is mentioned in Fig. 6a. The minimum mixture concentration, whose value is also mentioned in Fig. 6a is estimated to be in the top region of the cavity. In addition, inclined channel segregates, having positive mixture concentration, also form in the middle of the cavity. The segregation pattern in this region is banded type, having alternate positive and negative segregation. These banded patterns in the solute field are known as localized segregations (or channel segregates), which are a severe form of macrosegregation. It is estimated that the mixture concentration in these inclined channels is $\sim 11.0-18.0 \mathrm{wt} \% \mathrm{~Pb}$.

The mushy zone is shown by the liquid fraction map in Fig. 6b. Because of the presence of channels, the liquid fraction contours show patterns that appear to be penetrating the mushy region (Fig. 6b). The flow pattern indicated by streamlines along with the superimposed segregation map in the cavity is displayed in Fig. 6c. For the present case with cooperating thermosolutal conditions, 'counter-clockwise' flow loop can be seen. In the inclined channel region, the fluid flow enters those channels from above and follows them due to their lower flow resistance. The higher liquid fraction in the channels (see Fig. 6b) creates smaller flow resistance.

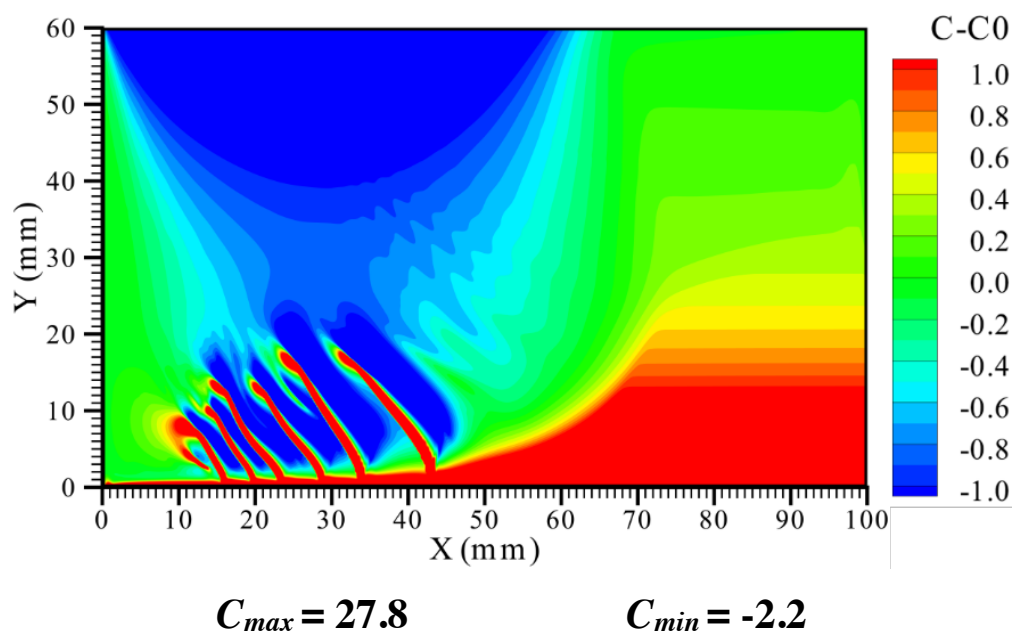




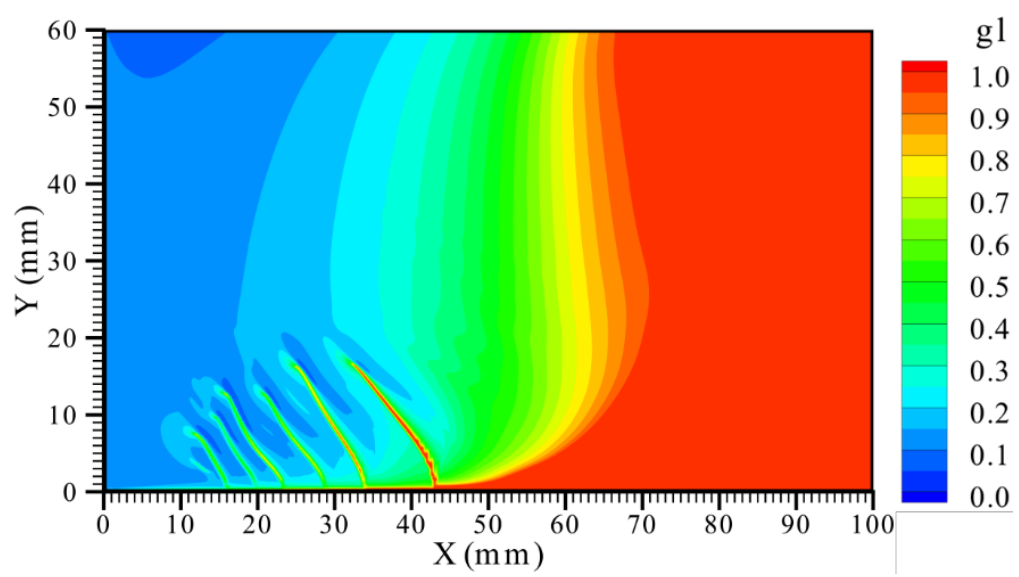

(b)

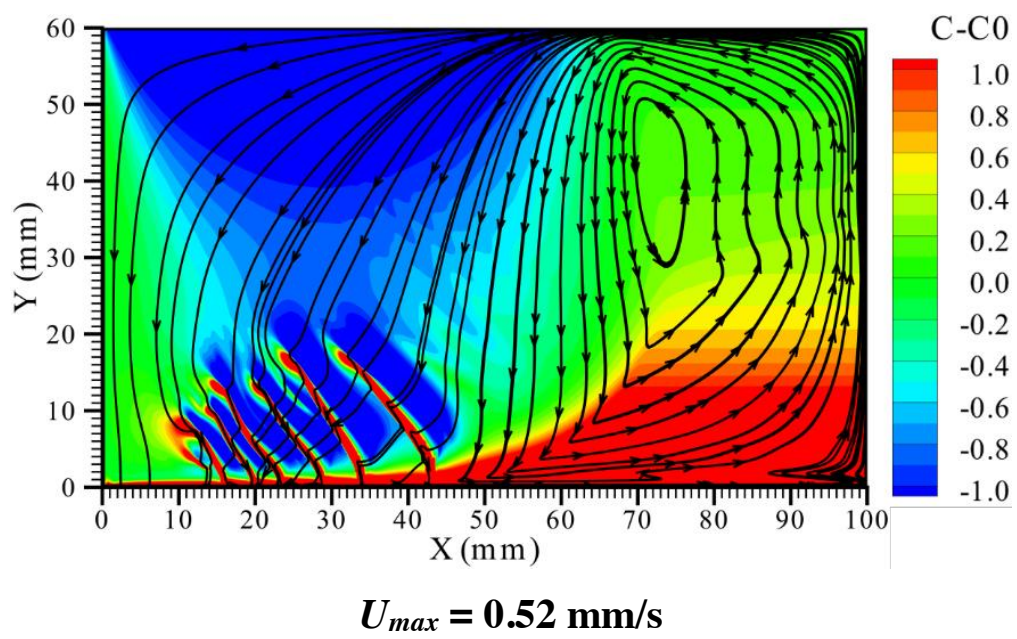

(c)

Figure 6: Maps of (a) macrosegregation (b) liquid fraction (c) macrosegregation with superimposed streamlines in the solidifying cavity at $400 \mathrm{~s}$. Macrosegregation is shown by concentration distribution $\left(C-C_{0}\right)$ in wt \% where $C$ is the concentration of $\mathrm{Pb}$ in wt $\%$ and $C_{0}$ is the nominal concentration of $\mathrm{Pb}$ in the alloy ( $=5 \mathrm{wt} \%)$.

Based on the discussions provided earlier regarding the dependence of segregation tendencies on the flow direction and the heat extraction, the formation of banded segregation having alternate positive and negative segregation in the inclined channel region is explained. Figure 7 a displays a zoomed image of the segregation map in the channel region near to the bottom of cavity at $400 \mathrm{~s}$. The fluid flow that follows the channels in the mush changes direction rather abruptly with respect to the smooth diffusive temperature field (see Fig. 7b). In Fig. 7b, we notice a specific change in direction of the velocity within and outside the channel and almost vertical temperature contours. It was estimated that in the channels the velocity of the liquid is oriented to the temperature gradient such that $\vec{v}_{l} \cdot \nabla T$ is positive (see the map of $\vec{v}_{l} \cdot \nabla T$ in Fig. 7b), which creates a tendency to form positive segregation [11-12]. However, in the adjacent regions of the channels, the velocity of liquid is oriented to the temperature gradient such that $\vec{v}_{l} \cdot \nabla T$ is negative, which creates a tendency to form negative segregation [11-12]. It leads to alternating zones of positive and negative $\vec{v}_{l} \cdot \nabla T$ (Fig. 7b) 
and therefore of segregation, which finally creates a banded segregation structure in the channel regions.
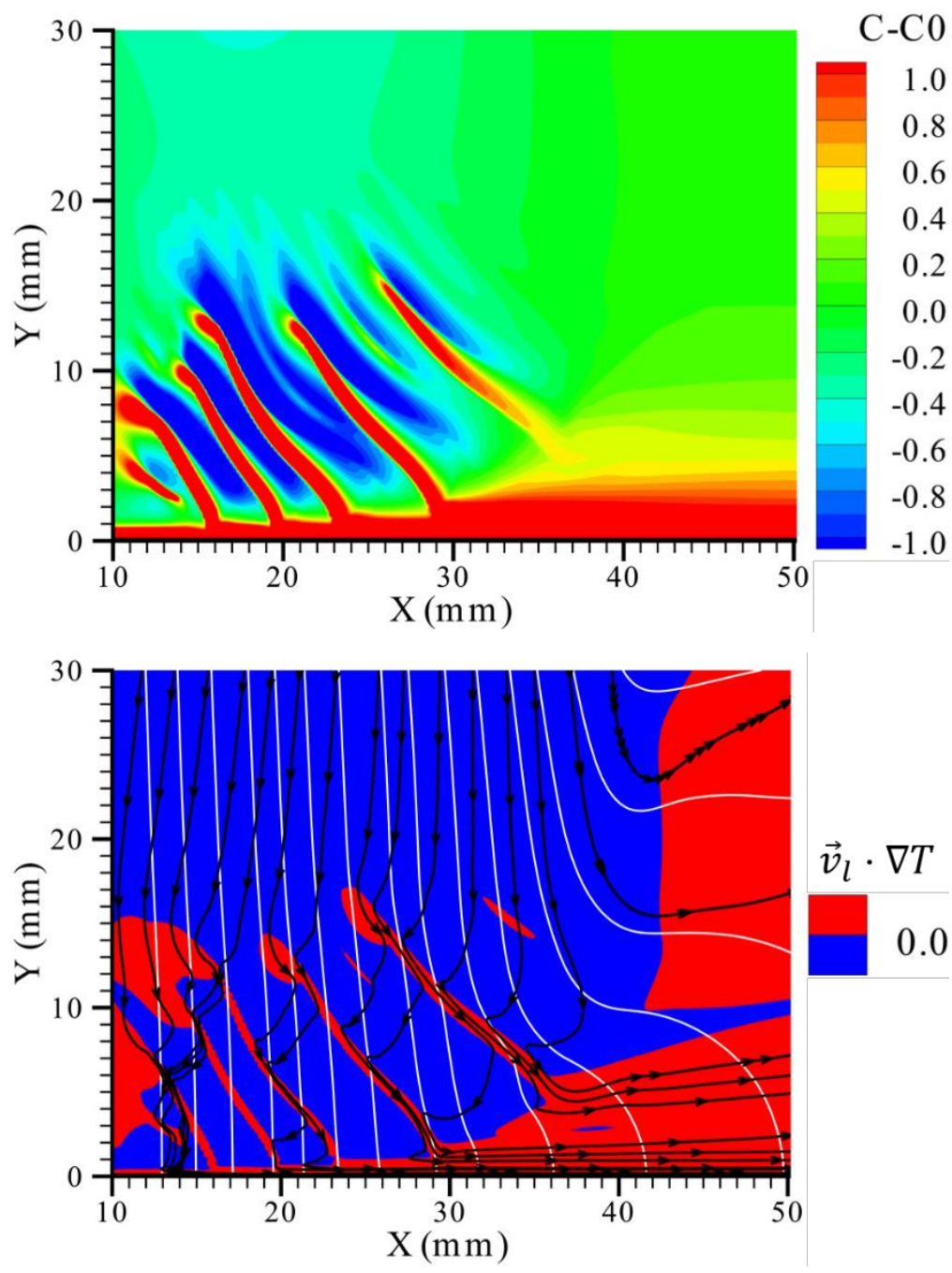

(b)

Figure 7: The formation of channel segregates in the bottom of the cavity (zoomed image) at $140 \mathrm{~s}$ : (a) segregation $\left(C-C_{0}\right)$ in wt \% (b) map of $\vec{v}_{l} \cdot \nabla T$ with superimposed streamlines (black) and isotherms (white).

\subsection{Demonstration of the instability criterion in predicting channel locations}

This section will focus on discussions (i) how the new instability criterion characterizes and predicts the channel segregates in comparison to the numerical simulations and (ii) how it is better than some existing channel segregations criterion (for example, the remelting criterion).

The predicted channel segregates shown in Fig. 6a are similar to those observed by Fredriksson and Nilsson [8] for $\mathrm{Sn}-10 \mathrm{wt} \% \mathrm{~Pb}$ alloy where they occurred because of instabilities in the mushy zone. As discussed in Sec. 2, any perturbation initiated can amplify 
in high- $g_{l}$ regions due to a very low value of $\frac{K}{g_{l}}\left(\frac{d K}{d g_{l}}\right)^{-1}$ (see Fig. 2b) in these regions. This condition is favorable for the amplification of the perturbations according to Eq. (13).

The above discussion will be more clear when we show the map of the criterion given by Eq. (13). We rearrange the criterion given in Eq. (13) and define the numerical value of the New instability criterion $(N I C)$ as

$$
N I C=\vec{v}_{l} \cdot \nabla T-\frac{K}{g_{l}}\left(\frac{d K}{d g_{l}}\right)^{-1}\left(\vec{v}_{T} \cdot \nabla T\right)
$$

We also define the numerical value of Fleming's remelting criterion [28] (FRC) as

$$
F R C=\vec{v}_{l} \cdot \nabla T-\vec{v}_{T} \cdot \nabla T
$$

The positive values of NIC imply satisfaction of the criterion for amplification of perturbation (i.e., $\left.\frac{\partial\left(\delta g_{l}\right)}{\partial t}>0\right)$ given in Eq. (13). In other words, in the regions of positive NIC, any perturbation generated is likely to amplify and hence at those locations, channels may form. However, in the regions of negative NIC, perturbations are likely to dampen and channels may not form at those locations. Similarly, the positive values of $F R C$ imply satisfaction of the criterion for remelting $\left(\frac{\partial g_{l}}{\partial t}>0\right)$ and in those regions, channels may form due to remelting in the mush. In Eq. (15a) and $(15 \mathrm{~b}), \vec{v}_{T} \cdot \nabla T\left(=-\frac{\partial T}{\partial t}\right)$ is always positive. Similarly, $\frac{K}{g_{l}}\left(\frac{d K}{d g_{l}}\right)^{-1}$ in the second term of Eq. (15a) is always positive and lower than unity (see Fig. 2b). Therefore, the second term of Eq. (15a) and (15b) will always be positive. However, the sign of the first term of Eq. (15a) and (15b), i.e., $\vec{v}_{l} \cdot \nabla T$ depends on the orientation of the liquid velocity $\left(\vec{v}_{l}\right)$ to the temperature gradient $(\nabla T)$. In particular, it has a positive sign if $\vec{v}_{l}$ is oriented to $\nabla T$ at an angle less than $90^{\circ}$, otherwise, it has a negative sign. Based on these facts, both NIC and FRC are always negative for a negative value of $\vec{v}_{l} \cdot \nabla T$, i.e., if the flow has a velocity component oriented in the direction opposite of the temperature gradient. Only if the flow is oriented in the direction of the temperature gradient (positive value of $\vec{v}_{l} \cdot \nabla T$ ), NIC and FRC can be positive, indicating amplification of the perturbation and remelting, respectively. Moreover, since $\frac{K}{g_{l}}\left(\frac{d K}{d g_{l}}\right)^{-1}$ always has a positive but lower than unity value (according to Fig. 2b), NIC will always be larger than FRC for both positive and negative values of $\vec{v}_{l} \cdot \nabla T$. It is in line with the findings made earlier that any perturbation in $g_{l}$ can amplify even before the remelting criterion $\vec{v}_{l} \cdot \nabla T>\vec{v}_{T} \cdot \nabla T$ is satisfied. In the following, we discuss the numerically simulated results for the evolution of channel segregates with 
time and compare these results with those predicted by the new instability and remelting criterion.

Figure 8 and Figure 9 show the line and the color maps to depict the evolution of perturbations in the liquid fraction, velocity, pressure and temperature field as solidification progresses. Since the perturbations in liquid concentration are identical to those in temperature field as evident from the model, the perturbations in the liquid concentration filed are not shown. We observed that the influence of perturbations in the liquid fraction and flow field on the pressure and temperature field is negligible (see Fig. 8 and Fig. 9). Thus, the assumptions of negligible perturbations in the pressure, temperature and liquid concentration fields made in the derivation of new instability criteria are satisfied.
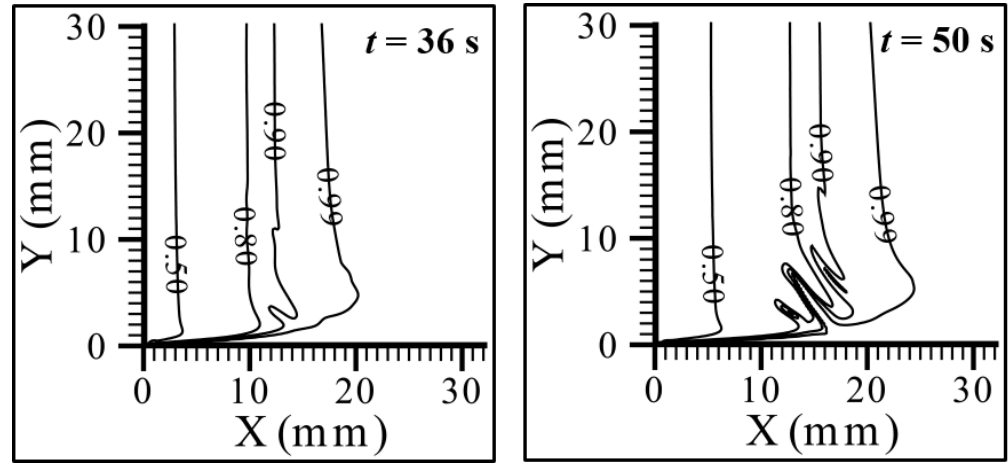

(a)
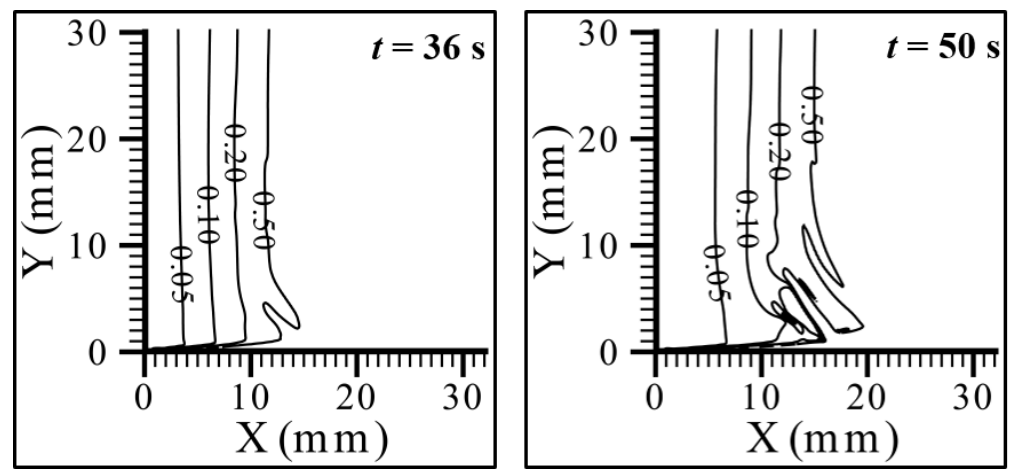

(b)
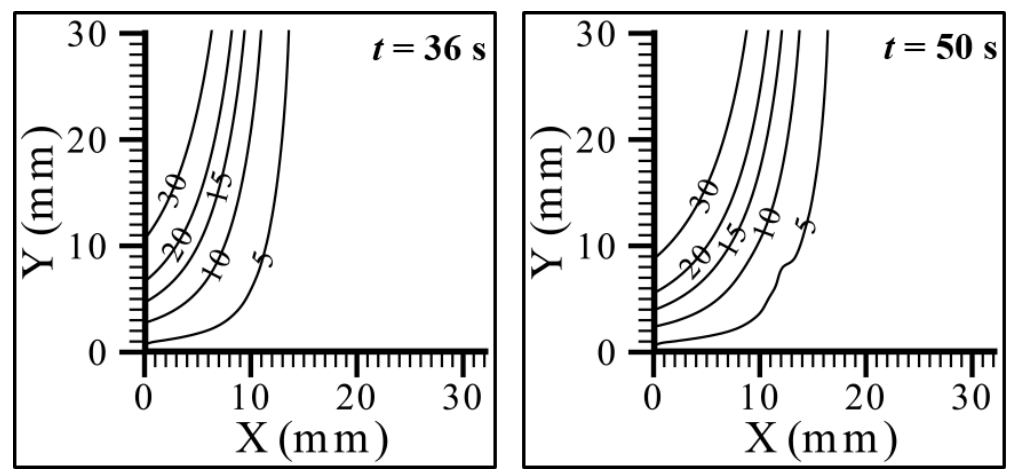
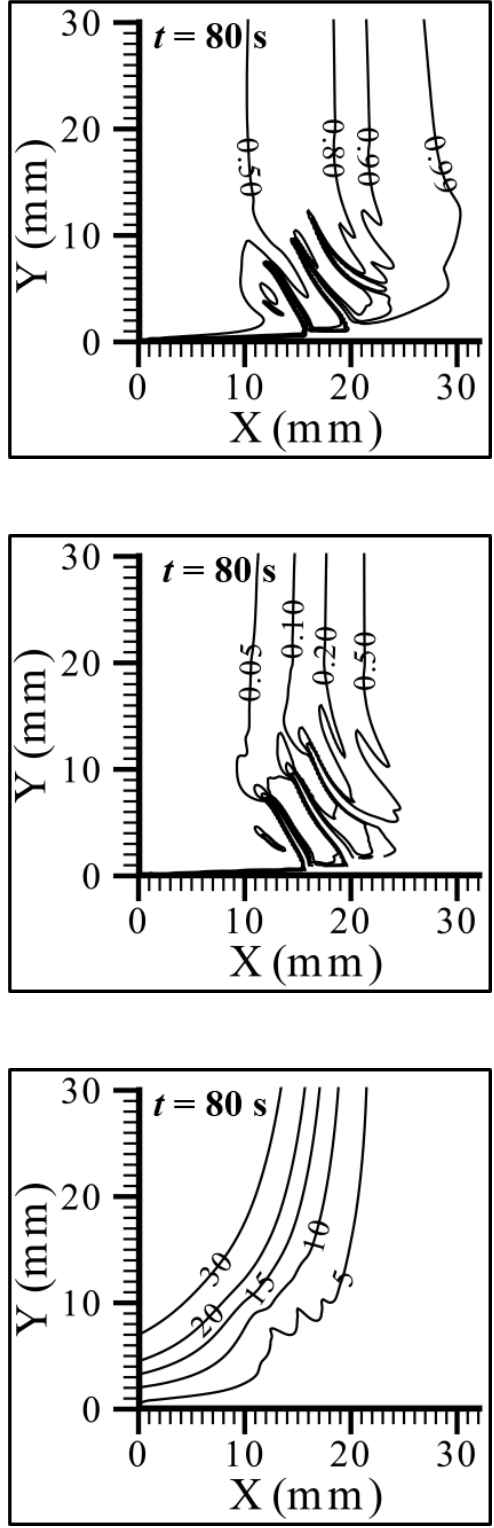

(c) 

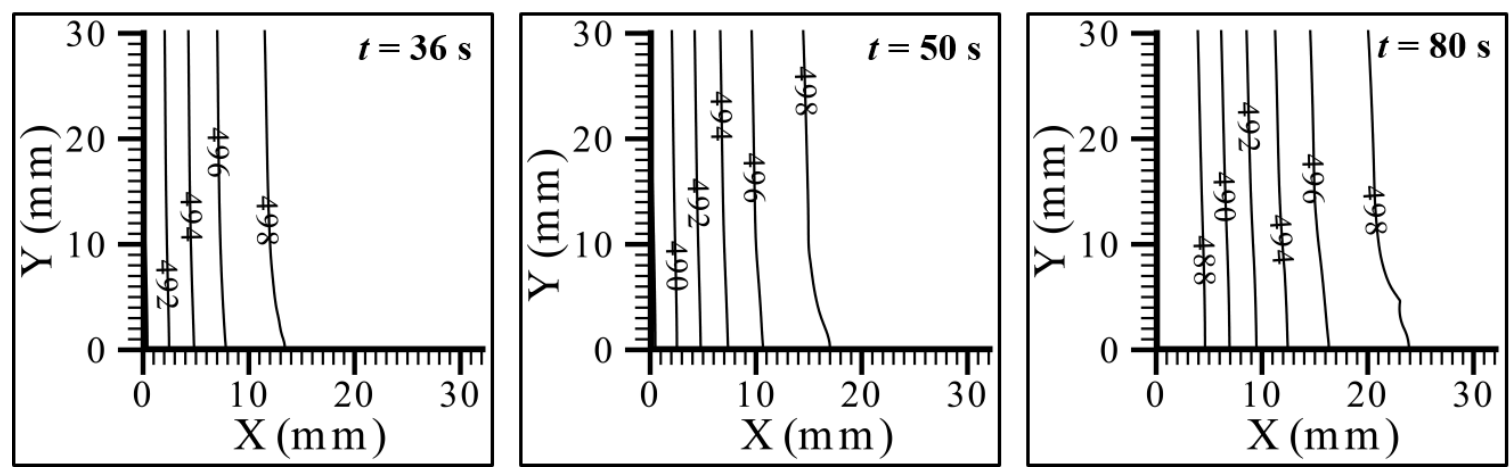

(d)

Figure 8: Iso-line maps show the perturbation in the (a) liquid fraction, (b) velocity magnitude $(\mathrm{mm} / \mathrm{s}),(\mathrm{c})$ pressure $(\mathrm{Pa})$ and $(\mathrm{d})$ temperature $(\mathrm{K})$ field at $t=36 \mathrm{~s}, 50 \mathrm{~s}$ and $80 \mathrm{~s}$, respectively. Maps are shown in the relevant regions, i.e., liquid fraction lower than 0.99.

g1: $\begin{array}{lllllllllll}0.0 & 0.1 & 0.2 & 0.3 & 0.4 & 0.6 & 0.7 & 0.8 & 0.9 & 1.0\end{array}$
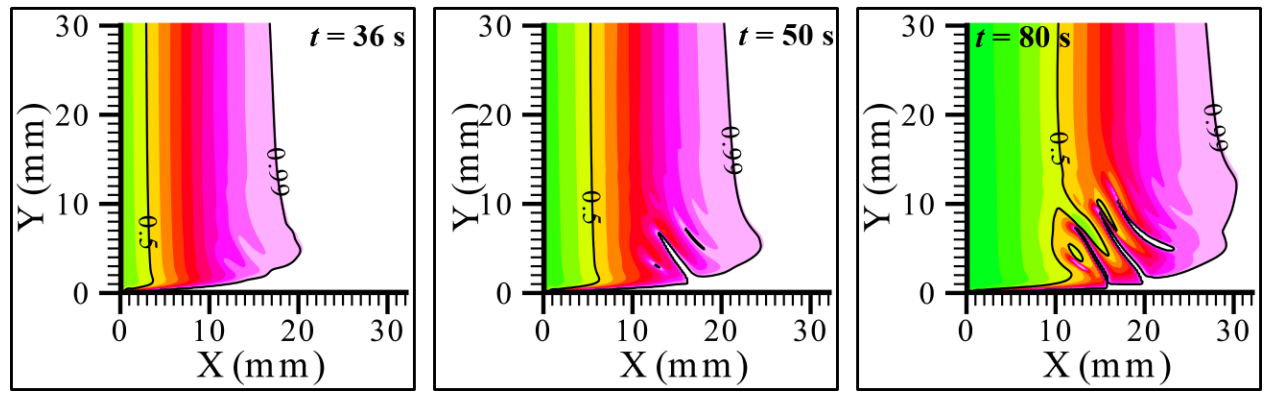

(a)

Vmag

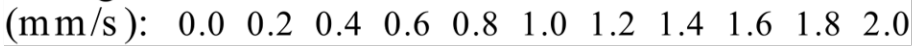
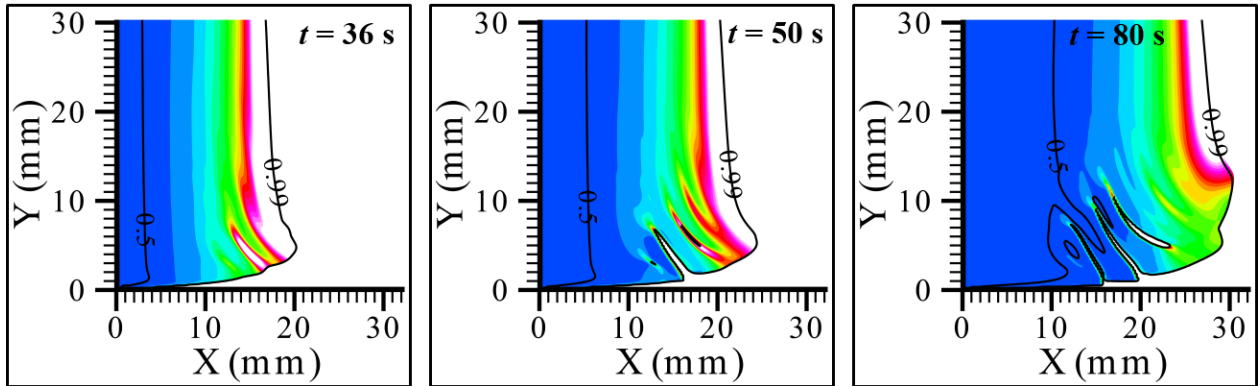

(b)

$\mathrm{P}(\mathrm{Pa}): \quad \begin{array}{llllllllllll}0 & 20 & 40 & 60 & 80 & 100 & 120 & 140 & 160 & 180 & 200\end{array}$
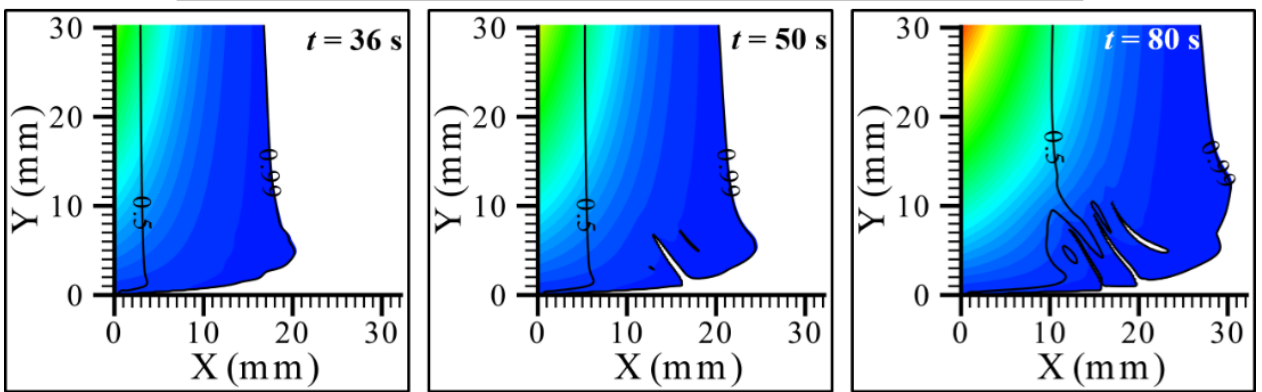

(c) 


\section{$\mathrm{T}(\mathrm{K}): 490491492493494495496497498499500$}
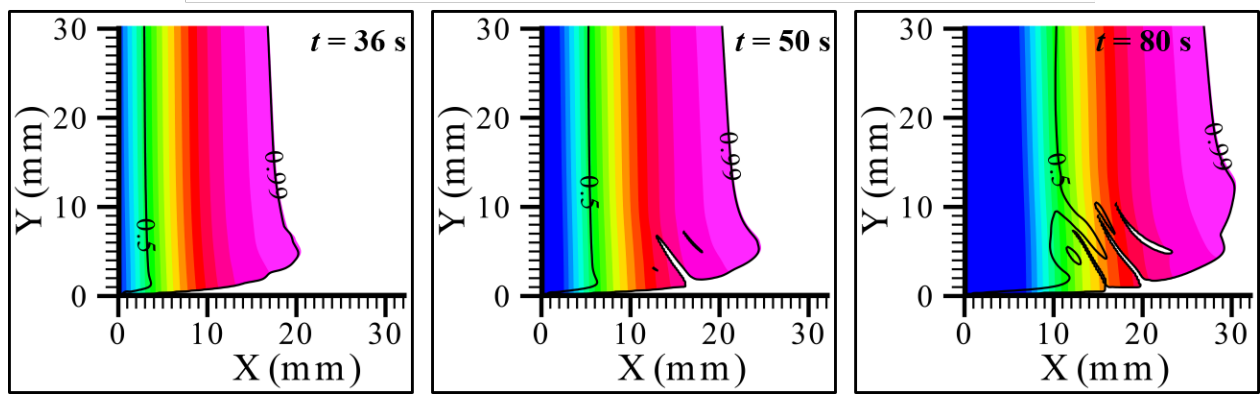

(d)

Figure 9: Color maps (superimposed with iso-lines of liquid fraction, 0.5 and 0.99) show the perturbation in the (a) liquid fraction, (b) velocity magnitude $(\mathrm{mm} / \mathrm{s})$, (c) pressure $(\mathrm{Pa})$ and

(d) temperature $(\mathrm{K})$ field at $\mathrm{t}=36 \mathrm{~s}, 50 \mathrm{~s}$ and $80 \mathrm{~s}$, respectively. Maps are shown in the relevant regions, i.e., liquid fraction lower than 0.99 .

In Fig. 10, we show the maps of liquid fraction, segregation, NIC and FRC in the solidifying cavity at $30 \mathrm{~s}, 36 \mathrm{~s}$ and $140 \mathrm{~s}$. It was estimated that at around time $t=30 \mathrm{~s}$, the first instance of amplification of the instability in the mushy zone appears. From Fig. 10a it can be seen that the liquid fraction contour in high- $g_{l}$ regions (liquid fraction more than 0.9) are perturbed. This is also reflected in the segregation map (Fig. 10b), which shows positive segregation zones along the perturbed liquid fraction. These positive segregation zones are the first instance when channel segregation in the cavity arises. From Figs. 10c and 10d (at $t$ $=30 \mathrm{~s}$ ), it can be seen that the NIC is positive along these channel segregation zones; however, $F R C$ is still negative. The first positive value of $F R C$ occurs at $t=36 \mathrm{~s}$ (see Fig 10c at $t=36 \mathrm{~s}$ ). It implies satisfaction of new instability criterion along the channel segregation zones but not of remelting criterion. It means the amplification of perturbation, which causes the initiation of channel segregation, is due to mush instability and not due to remelting. This result illustrates that the new instability criterion very well characterizes the initiation of channels. It also seems that the initiation of channel segregates is a direct consequence of the amplification of perturbations in high- $g_{l}$ regions (causing higher interdendritic velocity), as mentioned earlier, as the favorable conditions for amplifications of instabilities. It can also be noted that the new instability criterion involving a function of mushy zone permeability is able to capture the mush instability. It indirectly points out that the mush permeability (through the $\frac{K}{g_{l}}\left(\frac{d K}{d g_{l}}\right)^{-1}$ function) must be playing a key role in the amplification of the mush instability. Further, as we notice the perturbations in liquid fraction only in the high- $g_{l}$ regions (liquid fraction more than 0.9), it again supports the point mentioned in Fig. $2 \mathrm{~b}$ that such perturbations are more sensitive in the high- $g_{l}$ regions of the mushy zone. Later on, when few channel segregates have developed to a certain extent, some inclined channels and 
correspondingly channel segregates can be seen (see Fig. 10a, 10b at $t=140 \mathrm{~s}$ ). We observe five inclined channels at $t=140 \mathrm{~s}$. The predicted possible channel locations from the new instability criterion are very similar to the channel segregates found in the simulation results (see Fig. 10b and Fig. 10d at $t=140 \mathrm{~s}$ ) where the exact number ( 5 channels) and their proper length into the mushy zone is captured. However, with the remelting criterion, only three channels with shorter lengths are predicted (see Fig. 10b and Fig. 10c at $t=140 \mathrm{~s}$ ). From the remelting criterion, the length of the channel is shorter as at higher mush depth remelting does not occur and channels forms due to mush instability. The new instability criterion is able to capture the initial perturbations responsible for the formation of mush instability at larger mush depth. From these results, we can notice that predictions of channel defects in the casting based on remelting can severely under characterize these defects (e.g., their number and length).
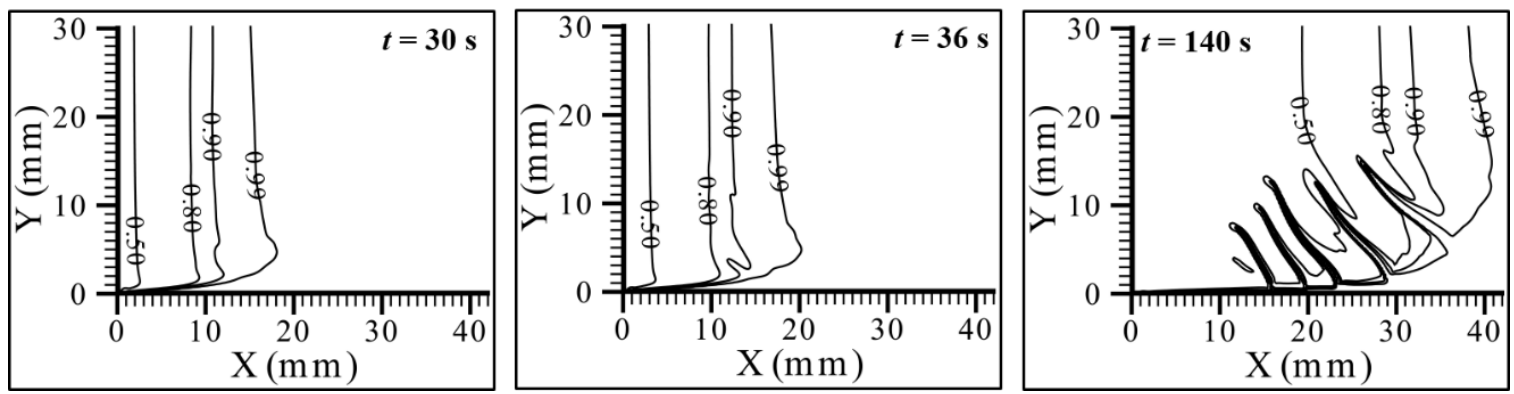

(a)

$\begin{array}{llllllllllll}\text { C-C } 0: ~ & -1.0 & -0.8 & -0.6 & -0.4 & -0.2 & 0.0 & 0.2 & 0.4 & 0.6 & 0.8 & 1.0\end{array}$
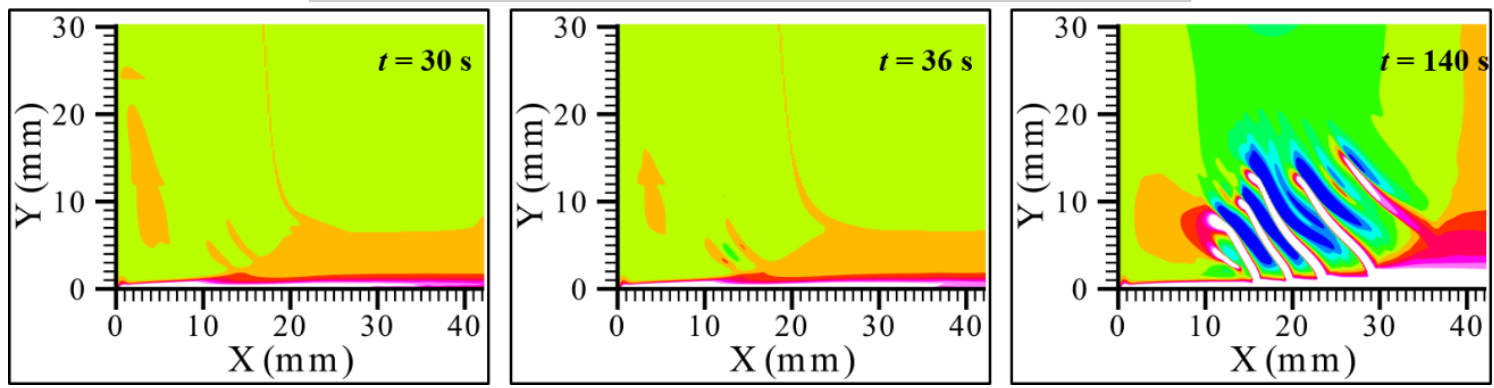

(b)

FRC: $\quad 0.000 \quad 0.002 \quad 0.004 \quad 0.006 \quad 0.008 \quad 0.010$
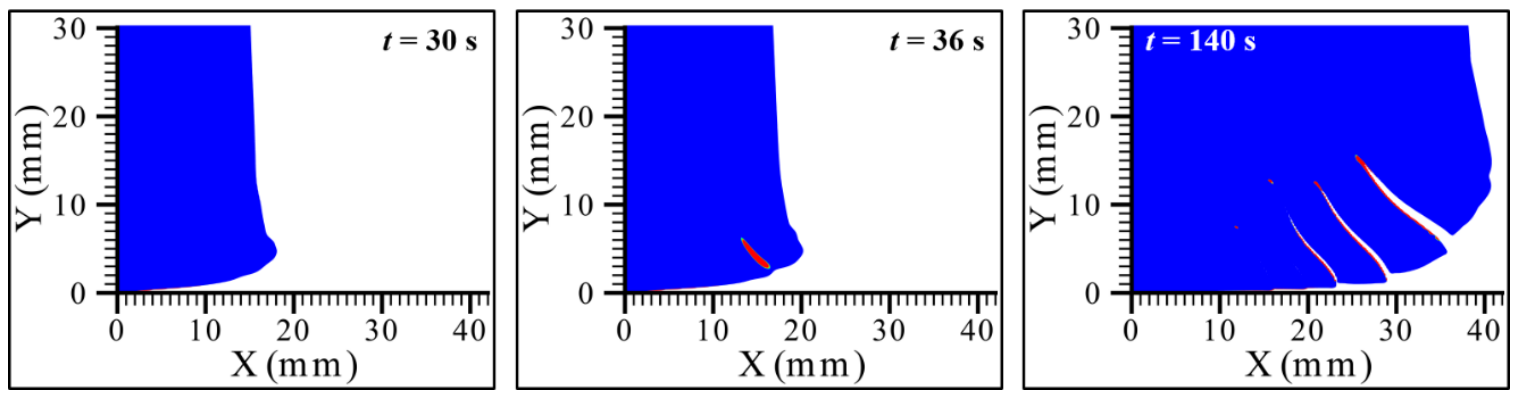

(c) 

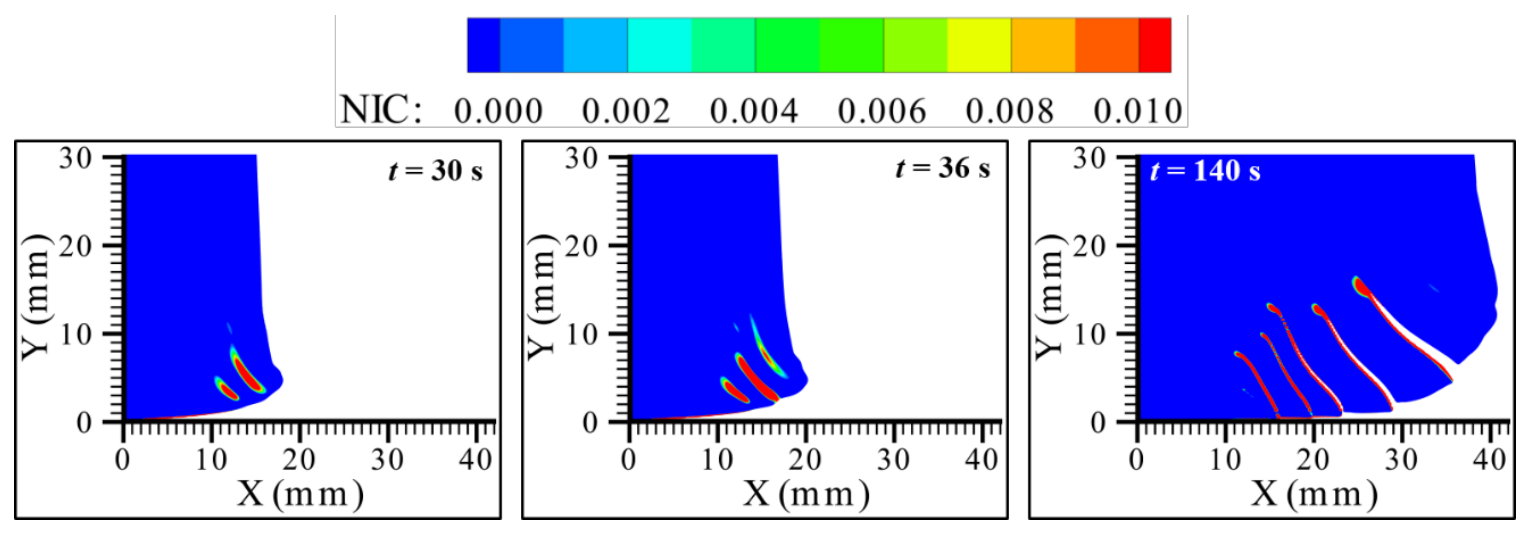

(d)

Figure 10: Maps of (a) liquid fraction (b) segregation (c) FRC (d) NIC in the solidifying cavity at $30 \mathrm{~s}, 36 \mathrm{~s}$ and $140 \mathrm{~s}$. FRC and NIC values are shown in the relevant regions, i.e., liquid fraction lower than 0.99 .

In Fig. 11, we show the maps of maximum values of $F R C$ and $N I C\left(F R C_{\max }\right.$ and $N I C_{\max }$, respectively) computed over time and the earliest times, $t_{F R C}$ (when $F R C>0$ ) and $t_{N I C}$ (when $N I C>0$ ) in the domain. The $F R C_{\max }$ and $N I C_{\max }$ are shown in the region where $F R C>$ 0 and NIC $>0$, respectively. We observed that the region where $F R C>0$ is smaller than the region where NIC $>0$ (see Fig. 11a and 11b). It implies that the NIC corresponds better to the region where channels are present. Further, we also noticed that the values of the earliest time, $t_{\mathrm{NIC}}\left(\right.$ when NIC $>0$ ) are smaller than $t_{F R C}$ (when $F R C>0$ ) (see Fig. 11c and 11d) in the region where channels are present. It implies that NIC is satisfied earlier in the channel areas.

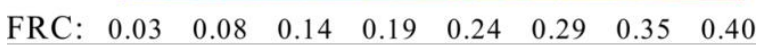

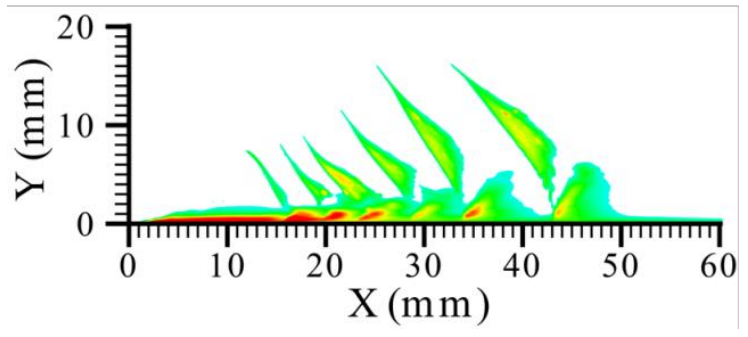

(a)

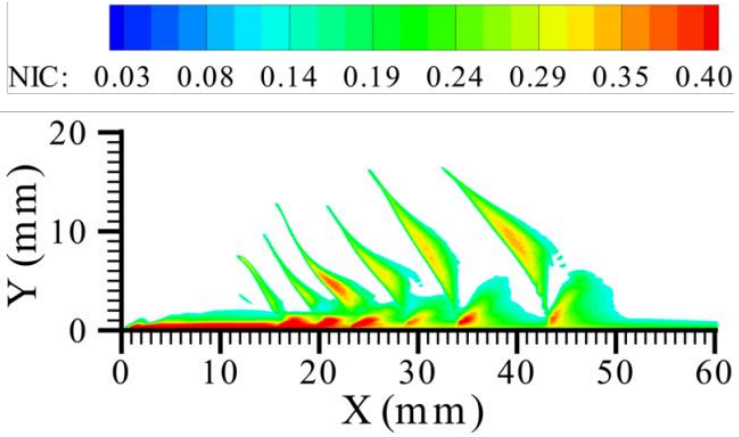

(b)

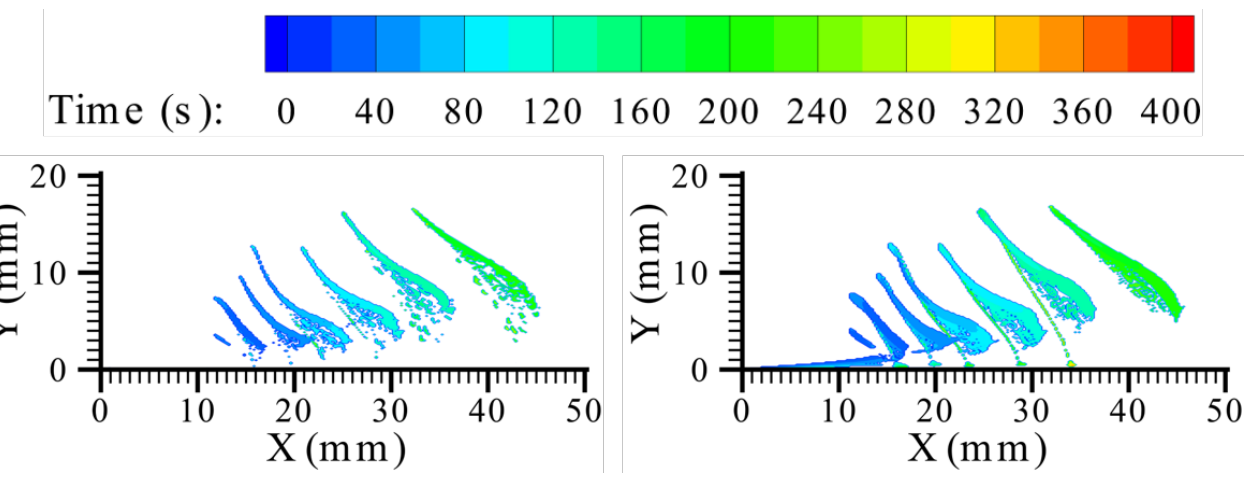

(c)

(d) 
Figure 11: Maps of (a) $F R C_{\max }$, (b) $N I C_{\max }$, (c) earliest time when $F R C>0$ ( $t_{F R C}$ ) and (d) earliest time when $N I C>0\left(t_{N I C}\right) . t_{F R C}$ and $t_{N I C}$ values are shown in the relevant regions, i.e., liquid fraction lower than 0.99 .

Figure 12 shows the variation of mixture concentration, NIC and FRC at $140 \mathrm{~s}$ along two inclined sections crossing through the channel segregation zone. Section 1 crosses the channel segregation zone from the root of the channels into the mush depth, as shown in Fig. 12a. Section 2 crosses the channel segregation zone close to the mid-length of channels into the mush depth. From Fig. 12b, it is interesting to note that the new instability criterion corresponds very well (i.e., shows positive values) to the five peaks in the mixture concentration corresponding to 5 channel segregates along the inclined section 1 . However, the remelting is not at all observed corresponding to these locations. For the inclined section 2 (Fig. 12c), the new instability criterion again corresponds well (i.e., shows positive values) to the five peaks in the mixture concentration corresponding to 5 channel segregates along the inclined section 2 . The remelting criteria also perform relatively better at these locations and predict three peaks along section 2. It implies that the few channels along the inclined section 2 could have witnessed remelting, but the channels along the inclined section 1 might not have observed remelting. It will be more clear when we show the time evolution of NIC and $F R C$ in the next plot.

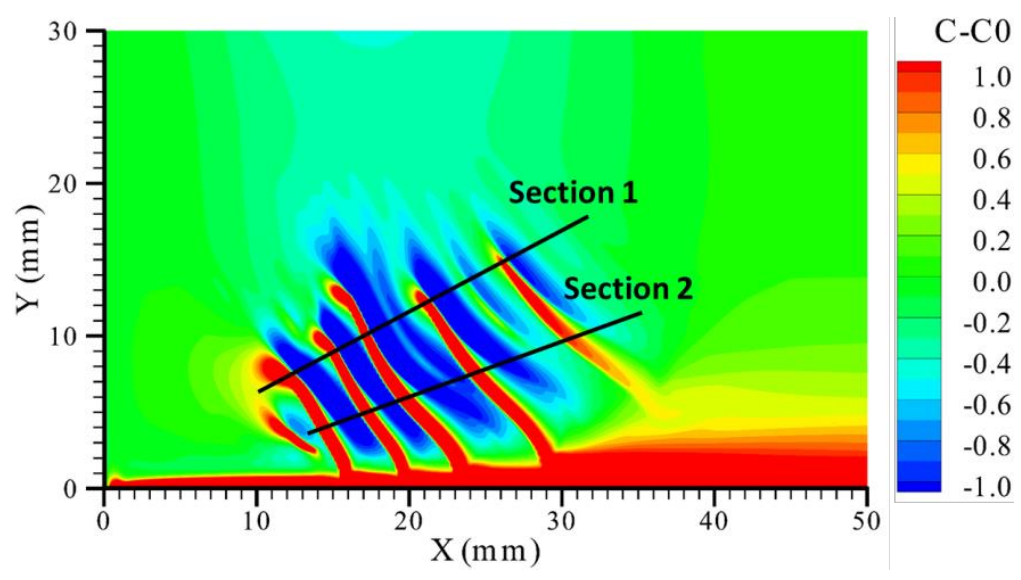

(a) 


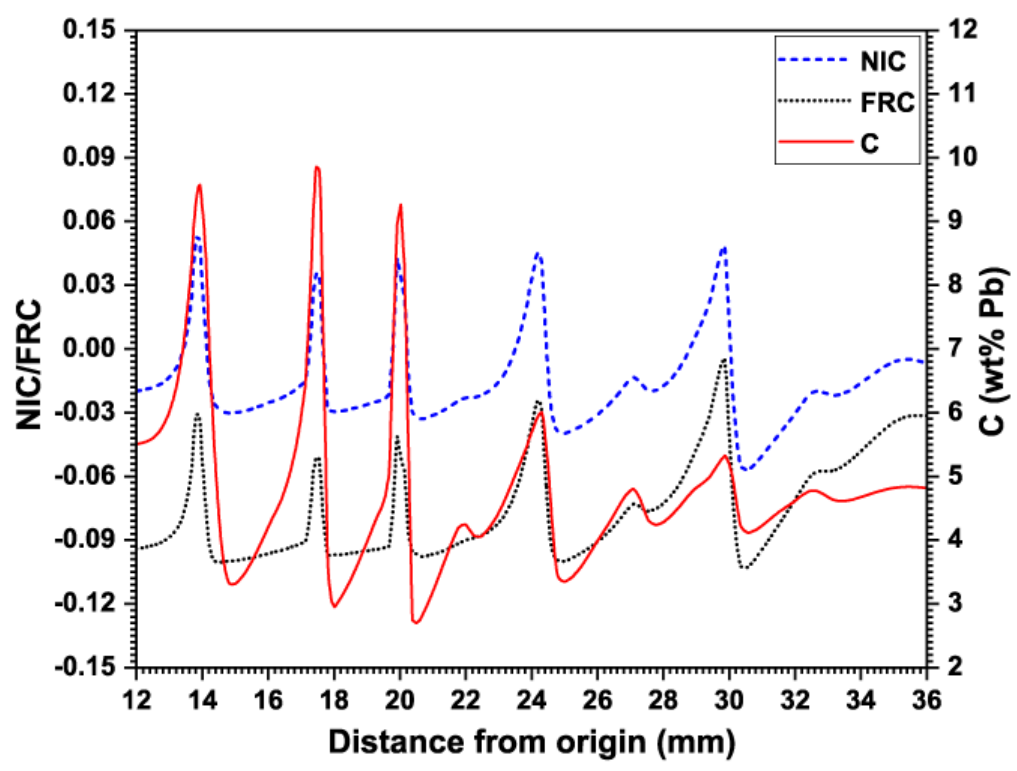

(b)

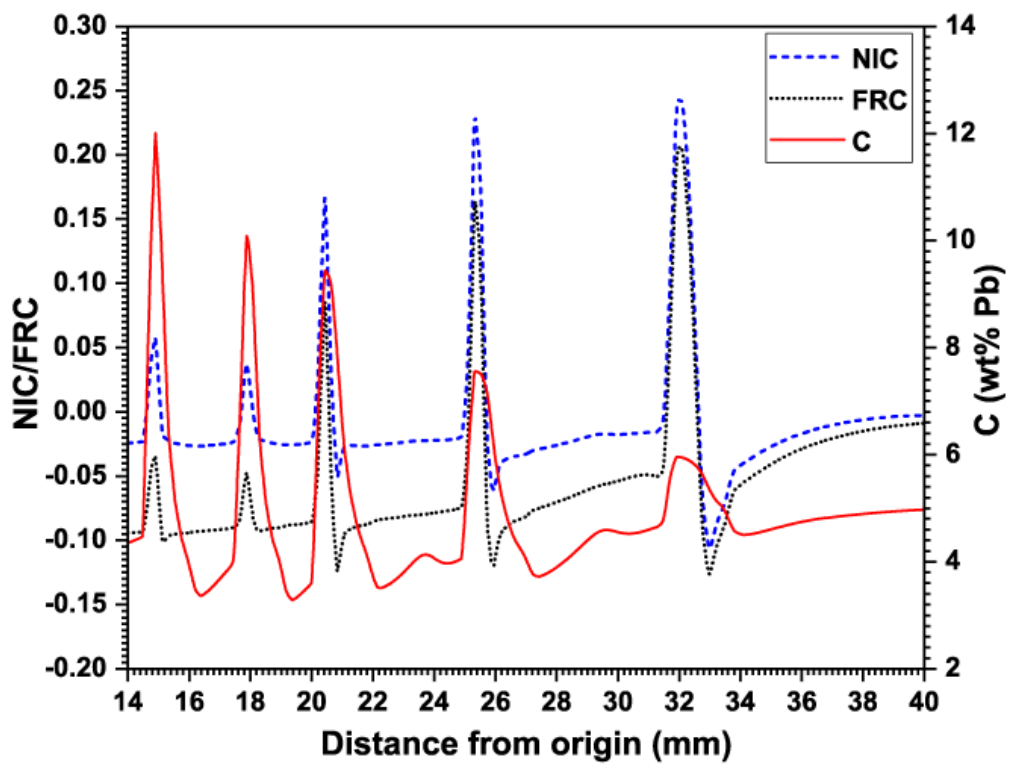

(c)

Figure 12: (a) Macrosegregation map marked with section 1 and section 2 inclined at an angle of $30^{\circ}$ and $20^{\circ}$ from $\mathrm{X}$ direction, respectively; Variation of mixture concentration, NIC and $F R C$ along (b) section 1 and (b) section 2 at $140 \mathrm{~s}$. The horizontal axis shows the distance of these lines from the origin.

Figure 13 displays the evolution of NIC, FRC, $g_{l}$ and mixture concentration with time at two locations in a selected channel - 'A' at the root (larger depth) of a channel and 'B' at the mid-depth of a channel (see Fig. 13a). In Fig. 13b, we can see that the perturbations at the location ' $\mathrm{A}$ ' started to amplify (positive $N I C$ ) at about $150 \mathrm{~s}$, which is followed by an increase in mixture concentration due to the formation of channel segregates. The liquid fraction does not show any remelting and hence $F R C$ remains negative. It implies that by remelting criterion, the correct length of channels may not be captured. At location ' $B$ ' at about $165 \mathrm{~s}$, we notice some remelting in the liquid fraction and hence $F R C$ becomes positive (see Fig. 13c). The perturbations at this location also started to amplify (positive NIC) at the same time, which is followed by an increase in mixture concentration. The mixture 
concentration keeps on increasing, suggesting the development of channel segregates. It implies that by remelting criterion, the correct duration of the development of channels may not be captured.

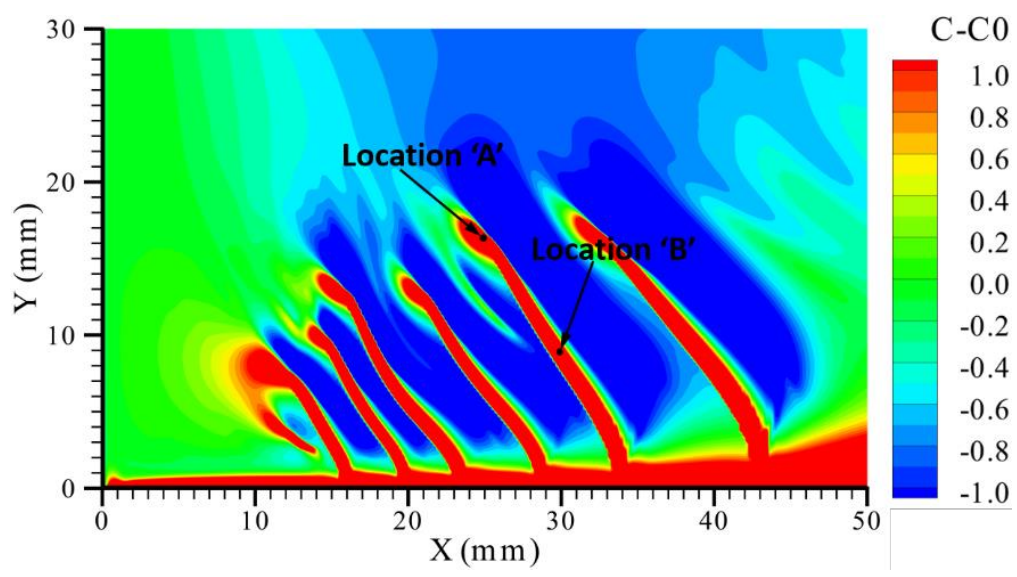

(a)

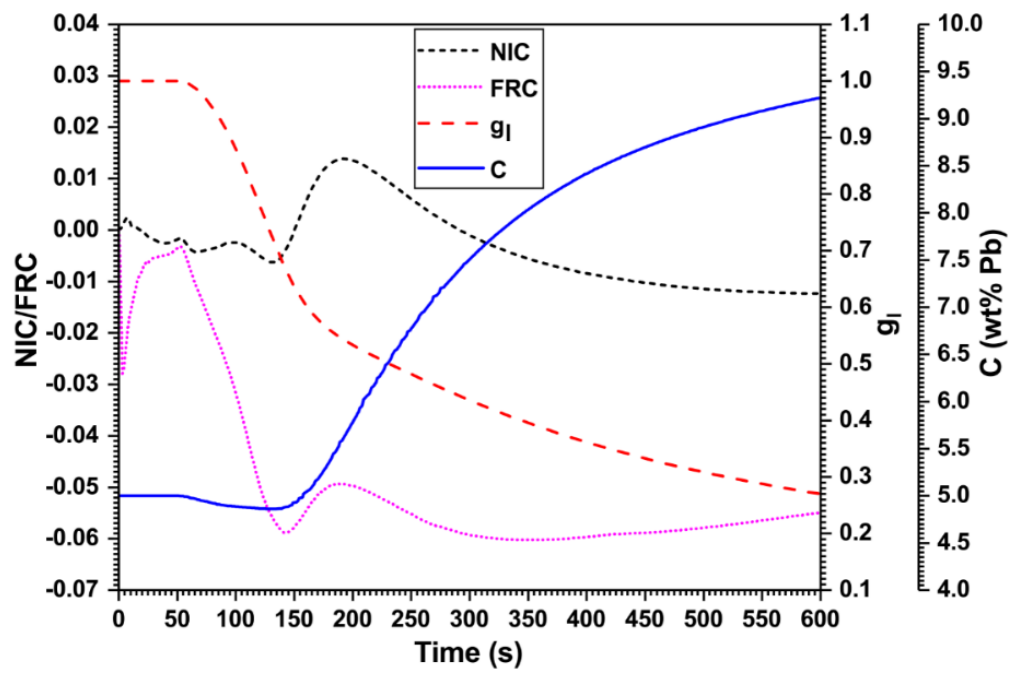

(b)

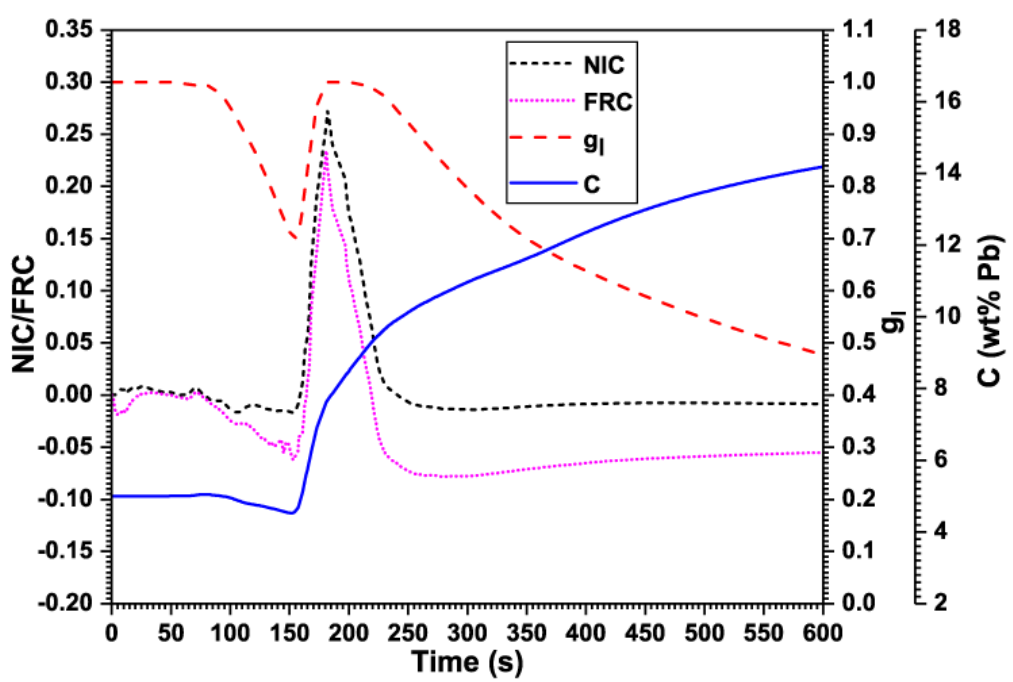

(c)

Figure 13: (a) Locations of two points selected for showing the time evolution plot. Location 'A' $(X=25 \mathrm{~mm}, Y=17 \mathrm{~mm})$ at the root (larger depth) of a channel, location 'B' $(X=30 \mathrm{~mm}$,

$Y=9 \mathrm{~mm}$ ) at the mid-depth of a channel; Evolution of NIC, FRC, $g_{l}$ and mixture concentration with time at (b) location 'A' (c) location 'B'. 
It can be noted from the past and the present results dealing with channel segregations during solidification that their formation is a dynamic thermosolutal fluid flow phenomenon taking place in spatially and temporally changing mushy zone. Therefore, the prediction of locations of their occurrence in the casting by some criteria based on static solidification parameters (such as remelting criterion [28]) can under characterize these defects in the casting; nevertheless, such criteria can predict these defects to some extent. In this regard, the new instability criterion, which considers the dynamic behavior of the mushy zone, by involving the mush permeability (spatial and temporal variation of liquid fraction in the mushy zone) and characteristic of the permeability law by including the derivative of the permeability with liquid fraction, can be able to predict the locations of such defects better. For these reasons, the new instability criterion characterizes the channel segregations observed in numerical simulations better than that by previously available remelting criterion [28]. Further, there is a general notion in the literature that the destabilization of the mushy zone front and the consequential formation of channel segregates are initiated by local remelting [28]. On the contrary, our results show that remelting in the mush may not be a necessary condition for the initiation of channels. The initiation of channels in our results is triggered by perturbations developed in the high- $g_{l}$ regions of the mush (for example, amplification of the instability of the solidification rate at the continuously advancing solidification front, i.e., $\left.\frac{\partial\left(\delta g_{l}\right)}{\partial t}>0\right)$.

\section{Conclusions}

A new model of mushy zone instability describing the relation between the mush instability and the mush permeability is presented. The capability of the new instability criterion in characterization and prediction of the channel segregates is illustrated by comparing the estimated possible channel locations from the developed criterion with that of numerically simulated channel segregations in a casting. Further, the numbers and locations of channel segregates estimated by the new instability model are also compared with those estimated using remelting criterion. From this study, the following main conclusions are drawn:

1. The new instability criterion developed for amplification of perturbations in the mushy zone depends on the interdendritic velocity, the isotherm velocity, the temperature gradient and explicitly on the mush permeability.

2. The new instability criterion suggests two favorable conditions for amplification of perturbation - a lower value of $\frac{K}{g_{l}}\left(\frac{d K}{d g_{l}}\right)^{-1}$ and/or a higher interdendritic velocity $\left(v_{l}\right)$. 
3. The permeability and its derivative with respect to liquid fraction (the $\frac{K}{g_{l}}\left(\frac{d K}{d g_{l}}\right)^{-1}$ function) in the outer part of mushy zone (high- $g_{l}$ regions, liquid fraction more than 0.9 ) plays a key role in the amplification of the mush instability. The part of the mushy region near the liquidus is more prone to the initiation of such instabilities.

4. The new instability criterion very well characterizes and predicts the locations of channel segregates observed in the numerical simulations. It characterizes these channel segregates better than that by the previously available remelting criterion [28]. The predictions of channel segregates based on remelting severely under characterize these defects (e.g., their number and length) in the casting.

5. The remelting in the mush is not a necessary condition for the initiation of channels. The initiation of channels is triggered by perturbations developed in the high- $g_{l}$ regions of the mush.

Quantification of the new instability criterion in terms of the dependent process parameters may further (i) explain the onset of instabilities in the mushy zone; (ii) predict a range of various parameters leading to amplification of mush instabilities; and (iii) estimate the possible channel segregations regimes in the casting, more accurately.

\section{Declaration of Competing Interest}

The authors declare that they have no known competing financial interests or personal relationships that could have appeared to influence the work reported in this paper

\section{Acknowledgments}

The financial support of MHRD, India (Grant No. MHRD/ME/2016408H) is gratefully acknowledged. Authors would like to thank the high performance computing (HPC2013) facility at I.I.T. Kanpur, India, for performing the simulations.

\section{References}

[1] A. Kumar, M. Založnik, H. Combeau, Study of the influence of mushy zone permeability laws on macro- and meso-segregations predictions, Int. J. Therm. Sci. 54 (2012) 33-47. https://doi.org/10.1016/j.ijthermalsci.2011.11.014.

[2] C. Prakash, V. Voller, On the numerical solution of continuum mixture equations describing binary solid-liquid phase change, Numer. Heat Transf. Part B. 15 (1989) 171-189. https://doi.org/https://doi.org/10.1080/10407798908944899. 
[3] W.D. Bennon, F.P. Incropera, A continuum model for momentum, heat and species transport in binary solid-liquid phase change systems-I. Model formulation, Int. J. Heat Mass Transf. 30 (1987) 2161-2170. https://doi.org/10.1016/0017-9310(87)90094-9.

[4] I. Vannier, H. Combeau, G. Lesoult, Numerical model for prediction of the final segregation pattern of bearing steel ingots, Mater. Sci. Eng. A. 173 (1993) 317-321. https://doi.org/10.1016/0921-5093(93)90236-8.

[5] V. Hatić, M. Cisternas Fernández, B. Mavrič, M. Založnik, H. Combeau, B. Šarler, Simulation of a macrosegregation benchmark in a cylindrical coordinate system with a meshless method, Int. J. Therm. Sci. 142 (2019) 121-133. https://doi.org/10.1016/j.ijthermalsci.2019.04.009.

[6] M. Cisternas Fernández, M. Založnik, H. Combeau, U. Hecht, Thermosolutal convection and macrosegregation during directional solidification of TiAl alloys in centrifugal casting, Int. J. Heat Mass Transf. 154 (2020) 119698. https://doi.org/10.1016/j.ijheatmasstransfer.2020.119698.

[7] S. Chakraborty, P. Dutta, Three-dimensional double-diffusive convection and macrosegregation during non-equilibrium solidification of binary mixtures, Int. J. Heat Mass Transf. 46 (2003) 2115-2134. https://doi.org/10.1016/S0017-9310(02)00530-6.

[8] H. Fredriksson, S.O. Nilsson, On the formation of macrosegregations in ingots, Metall. Trans. B. 9 (1978) 111-120. https://doi.org/10.1007/BF02673436.

[9] R. Boussaa, L. Hachani, O. Budenkova, V. Botton, D. Henry, K. Zaidat, H. Ben Hadid, Y. Fautrelle, Macrosegregations in $\mathrm{Sn}-3 \mathrm{wt} \% \mathrm{~Pb}$ alloy solidification: Experimental and 3D numerical simulation investigations, Int. J. Heat Mass Transf. 100 (2016) 680-690. https://doi.org/10.1016/j.ijheatmasstransfer.2016.04.120.

[10] N. Ahmad, H. Combeau, J.-L. Desbiolles, T. Jalanti, G. Lesoult, J. Rappaz, M. Rappaz, C. Stomp, Numerical simulation of macrosegregation : a comparison between finite volume method and finite element method predictions and a confrontation with experiments, Metall. Mater. Trans. A. 29 (1998) 617-630. https://doi.org/https://doi.org/10.1007/s11661-998-0143-9.

[11] H. Combeau, M. Založnik, S. Hans, P.E. Richy, Prediction of macrosegregation in steel ingots: Influence of the motion and the morphology of equiaxed grains, Metall. Mater. Trans. B Process Metall. Mater. Process. Sci. 40 (2009) 289-304. https://doi.org/10.1007/s11663-008-9178-y.

[12] M. Založnik, H. Combeau, Thermosolutal flow in steel ingots and the formation of mesosegregates, Int. J. Therm. Sci. 49 (2010) 1500-1509. https://doi.org/10.1016/j.ijthermalsci.2010.04.011.

[13] J. Jain, A. Kumar, P. Dutta, Numerical studies on channel formation and growth during solidification: Effect of process parameters, J. Heat Transfer. 129 (2007) 548-558. https://doi.org/10.1115/1.2709660.

[14] J. Li, M. Wu, J. Hao, A. Ludwig, Simulation of channel segregation using a two-phase columnar solidification model - Part I: Model description and verification, Comput. Mater. Sci. 55 (2012) 407-418. https://doi.org/10.1016/j.commatsci.2011.12.037.

[15] J. Li, M. Wu, J. Hao, A. Kharicha, A. Ludwig, Simulation of channel segregation using a two-phase columnar solidification model - Part II: Mechanism and parameter study, 
Comput. Mater. Sci. 55 (2012) 419-429.

https://doi.org/10.1016/j.commatsci.2011.12.021.

[16] A. Plotkowski, M.J.M. Krane, On the numerical prediction of channel segregation, Int. J. Heat Mass Transf. 100 (2016) 11-23. https://doi.org/10.1016/j.ijheatmasstransfer.2016.04.048.

[17] Y.F. Cao, Y. Chen, D.Z. Li, Formation mechanism of channel segregation in carbon steels by inclusion flotation: X-ray microtomography characterization and multi-phase flow modeling, Acta Mater. 107 (2016) 325-336.

https://doi.org/10.1016/j.actamat.2016.02.004.

[18] Y. Zheng, M. Wu, E. Karimi-Sibaki, A. Kharicha, A. Ludwig, Use of a mixed columnar-equiaxed solidification model to analyse the formation of as-cast structure and macrosegregation in a Sn-10 wt $\% \mathrm{~Pb}$ benchmark experiment, Int. J. Heat Mass Transf. 122 (2018) 939-953. https://doi.org/10.1016/j.ijheatmasstransfer.2018.02.012.

[19] M. Torabi Rad, C. Beckermann, A truncated-Scheil-type model for columnar solidification of binary alloys in the presence of melt convection, Materialia. 7 (2019) 100364. https://doi.org/10.1016/j.mtla.2019.100364.

[20] A. Kumar, B. Dussoubs, M. Založnik, H. Combeau, Effect of discretization of permeability term and mesh size on macro- and meso-segregation predictions, J. Phys. D. Appl. Phys. 42 (2009) 105503. https://doi.org/10.1088/0022-3727/42/10/105503.

[21] A. Kumar, M. Založnik, H. Combeau, B. Goyeau, D. Gobin, A numerical simulation of columnar solidification: Influence of inertia on channel segregation, Model. Simul. Mater. Sci. Eng. 21 (2013) 045016. https://doi.org/10.1088/0965-0393/21/4/045016.

[22] D.R. Poirier, Permeability for flow of interdendritic liquid in columnar-dendritic alloys, Metall. Trans. B. 18 (1987) 245-255. https://doi.org/10.1007/BF02658450.

[23] A.K. Singh, B. Basu, A. Ghosh, Role of appropriate permeability model on numerical prediction of macrosegregation, Metall. Mater. Trans. B Process Metall. Mater. Process. Sci. 37 (2006) 799-809. https://doi.org/10.1007/s11663-006-0062-3.

[24] M.C. Schneider, C. Beckermann, A numerical study of the combined effects of microsegregation, mushy zone permeability and flow, caused by volume contraction and thermosolutal convection, on macrosegregation and eutectic formation in binary alloy solidification, Int. J. Heat Mass Transf. 38 (1995) 3455-3473. https://doi.org/10.1016/0017-9310(95)00054-D.

[25] S. Chakraborty, P. Dutta, Effects of dendritic arm coarsening on macroscopic modelling of solidification of binary alloys, Mater. Sci. Technol. 17 (2001) 1531-1538. https://doi.org/10.1179/026708301101509782.

[26] D.R. Poirier, S. Ganesan, Permeabilities for flow of interdendritic liquid in equiaxial structures, Mater. Sci. Eng. A. 157 (1992) 113-123. https://doi.org/10.1016/09215093(92)90105-A.

[27] R.F. Katz, M.G. Worster, Simulation of directional solidification, thermochemical convection, and chimney formation in a Hele-Shaw cell, J. Comput. Phys. 227 (2008) 9823-9840. https://doi.org/10.1016/j.jcp.2008.06.039. 
[28] R. Mehrabian, M. Keane, M.C. Flemings, Interdendritic fluid flow and macrosegregation; influence of gravity, Metall. Mater. Trans. 1 (1970) 1209-1220. https://doi.org/10.1007/BF02900233.

[29] M. Simpson, M. Yerebakan, M.C. Flemings, Influence of dendrite network defects on channel segregate growth, Metall. Trans. A. 16A (1985) 1687-1689.

[30] M.J.M. Krane, F.P. Incropera, Experimental validation of continuum mixture model for binary alloy solidification, J. Heat Transfer. 119 (1997) 783-791. https://doi.org/10.1115/1.2824183.

[31] R. Nasser-Rafi, R. Deshmukh, D.R. Poirier, Flow of interdendritic liquid and permeability in pb-20 Wt Pct Sn alloys, Metall. Trans. A. 16 (1985) 2263-2271. https://doi.org/10.1007/BF02670426.

[32] S. Ganesan, D.R. Poirier, Conservation of mass and momentum for the flow of interdendritic liquid during solidification, Metall. Trans. B. 21 (1990) 173-181. https://doi.org/10.1007/BF02658128.

[33] B. Goyeau, T. Benihaddadene, D. Gobin, M. Quintard, Numerical calculation of the permeability in a dendritic mushy zone, Metall. Mater. Trans. B. 30 (1999) 613-622. https://doi.org/10.1007/s11663-999-0022-9.

[34] D.J. Hebditch, J.D. Hunt, Observations of Ingot Macrosegregation on Model Systems, Metallurgical Transactions, 5 (1974) 1557-1564. https://doi.org/10.1007/BF02646326.

[35] L. Hachani, K. Zaidat, B. Saadi, X.D. Wang, Y. Fautrelle, Solidification of Sn-Pb alloys: Experiments on the influence of the initial concentration, Int. J. Therm. Sci. 91 (2015) 34-48. https://doi.org/10.1016/j.ijthermalsci.2015.01.007.

[36] L. Hachani, K. Zaidat, Y. Fautrelle, Multiscale statistical analysis of the tin-lead alloy solidification process, Int. J. Therm. Sci. 110 (2016) 186-205. https://doi.org/10.1016/j.ijthermalsci.2016.07.001. 